\title{
Seasonal cycle, size dependencies, and source analyses of aerosol optical properties at the SMEAR II measurement station in Hyytiälä, Finland
}

\author{
A. Virkkula ${ }^{1,2}$, J. Backman ${ }^{1}$, P. P. Aalto ${ }^{1}$, M. Hulkkonen ${ }^{1}$, L. Riuttanen ${ }^{1}$, T. Nieminen ${ }^{1}$, M. dal Maso ${ }^{1}$, L. Sogacheva ${ }^{2}$, \\ G. de Leeuw ${ }^{1,2}$, and M. Kulmala ${ }^{1}$ \\ ${ }^{1}$ Department of Physics, University of Helsinki, 00014, Helsinki, Finland \\ ${ }^{2}$ Finnish Meteorological Institute, 00560, Helsinki, Finland
}

Received: 16 November 2010 - Published in Atmos. Chem. Phys. Discuss.: 9 December 2010

Revised: 15 April 2011 - Accepted: 3 May 2011 - Published: 12 May 2011

\begin{abstract}
Scattering and absorption were measured at the Station for Measuring Ecosystem-Atmosphere Relations (SMEAR II) station in Hyytiälä, Finland, from October 2006 to May 2009. The average scattering coefficient $\sigma_{\mathrm{SP}}(\lambda=$ $550 \mathrm{~nm}) 18 \mathrm{Mm}^{-1}$ was about twice as much as at the Pallas Global Atmosphere Watch (GAW) station in Finnish Lapland. The average absorption coefficient $\sigma_{\mathrm{AP}}(\lambda=550 \mathrm{~nm})$ was $2.1 \mathrm{Mm}^{-1}$. The seasonal cycles were analyzed from hourly-averaged data classified according to the measurement month. The ratio of the highest to the lowest average $\sigma_{\mathrm{SP}}$ and $\sigma_{\mathrm{AP}}$ was $\sim 1.8$ and $\sim 2.8$, respectively. The average single-scattering albedo $\left(\omega_{0}\right)$ was 0.86 in winter and 0.91 in summer. $\sigma_{\mathrm{SP}}$ was highly correlated with the volume concentrations calculated from number size distributions in the size range $0.003-10 \mu \mathrm{m}$. Assuming that the particle density was $1.5 \mathrm{~g} \mathrm{~cm}^{-3}$, the $\mathrm{PM}_{10}$ mass scattering efficiency was $3.1 \pm 0.9 \mathrm{~g} \mathrm{~m}^{-2}$ at $\lambda=550 \mathrm{~nm}$. Scattering coefficients were also calculated from the number size distributions by using a Mie code and the refractive index of ammonium sulfate. The linear regression yielded $\sigma_{\mathrm{SP}}($ modelled $)=1.046 \times$ $\sigma_{\mathrm{SP}}($ measured) for the data with the low nephelometer sample volume relative humidity $\left(\mathrm{RH}_{\mathrm{NEPH}}=30 \pm 9 \%\right)$ and $\sigma_{\mathrm{SP}}($ modelled $)=0.985 \times \sigma_{\mathrm{SP}}($ measured $)$ when $\mathrm{RH}_{\mathrm{NEPH}}=$ $55 \pm 4 \%$. The effective complex refractive index was obtained by an iterative approach, by matching the measured and the modelled $\sigma_{\mathrm{SP}}$ and $\sigma_{\mathrm{AP}}$. The average effective complex refractive index was $(1.517 \pm 0.057)+(0.019 \pm 0.015) i$ at $\lambda=550 \mathrm{~nm}$. The iterated imaginary part had a strong seasonal cycle, with smallest values in summer and highest in winter. The contribution of submicron particles to scattering was $\sim 90 \%$. The Ångström exponent of scattering, $\alpha_{\mathrm{SP}}$,
\end{abstract}

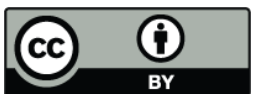

Correspondence to: A. Virkkula (aki.virkkula@helsinki.fi) was compared with the following weighted mean diameters: count mean diameter (CMD), surface mean diameter (SMD), scattering mean diameter (ScMD), condensation sink mean diameter (CsMD), and volume mean diameter (VMD). If $\alpha_{\mathrm{SP}}$ is to be used for estimating some measure of the size of particles, the best choice would be ScMD, then SMD, and then VMD. In all of these the qualitative relationship is similar: the larger the Angström exponent, the smaller the weighted mean diameter. Contrary to these, CMD increased with increasing $\alpha_{\mathrm{SP}}$ and CsMD did not have any clear relationship with $\alpha_{\text {SP. }}$. Source regions were estimated with backtrajectories and trajectory statistics. The geometric mean $\sigma_{\mathrm{SP}}$ and $\sigma_{\mathrm{AP}}$ associated with the grid cells in Eastern Europe were in the range $20-40 \mathrm{Mm}^{-1}$ and $4-6 \mathrm{Mm}^{-1}$, respectively. The respective geometric means of $\sigma_{\mathrm{SP}}$ and $\sigma_{\mathrm{AP}}$ in the grid cells over Norwegian Sea were in the range 5$10 \mathrm{Mm}^{-1}$ and $<1 \mathrm{Mm}^{-1}$. The source areas associated with high $\alpha_{\mathrm{SP}}$ values were norther than those for $\sigma_{\mathrm{SP}}$ and $\sigma_{\mathrm{AP}}$. The trajectory statistical approach and a simple wind sector classification agreed well.

\section{Introduction}

The boreal forests are a significant source of both primary and secondary particles that affect climate both directly and indirectly. To study biosphere-atmosphere interactions and all aspects of atmospheric aerosols in the forests, aerosols, trace gases and meteorological parameters have been measured at the SMEAR II (Station for Measuring Ecosystem-Atmosphere Relations) measurement station in Hyytiälä, southwestern central Finland $\left(61^{\circ} 50^{\prime} 47^{\prime \prime} \mathrm{N}\right.$, $24^{\circ} 17^{\prime} 42^{\prime \prime} \mathrm{E}, 181 \mathrm{~m}$ a.s.1.) continuously since 1996 , both by conducting long-term monitoring and in shorter field

Published by Copernicus Publications on behalf of the European Geosciences Union. 
campaigns (Hari and Kulmala, 2005). Numerous publications have been written on the properties and processes of aerosols measured at this site, for instance formation and growth, transport and removal of aerosols, their hygroscopic properties, ability to act as $\mathrm{CCN}$, etc. (e.g., Mäkelä et al., 1997; Kulmala et al., 1998, 2000, 2005; Aalto and Kulmala, 2000; Aalto et al., 2001; Dal Maso et al., 2002, 2005; Ehn et al., 2007; Manninen et al., 2009; Kyrö et al., 2009). One important aspect of aerosols has been paid negligible attention: light scattering and absorption, in other words those properties that are responsible for the aerosol direct radiative forcing of climate.

At SMEAR II aerosol optical properties have been measured with two instruments. Light absorption has been measured in the form of black carbon (BC) concentrations with a 7-wavelength aethalometer since 2004. The BC data were discussed earlier by Virkkula et al. (2007) and Hyvärinen et al. (2011). Actually, the term light-absorbing carbon (LAC) has been suggested to be more appropriate (Bond and Bergstrom, 2006). Here the term BC is used for practical reasons: it is used in the aethalometer data output and in the paper describing the algorithm applied here to calculate absorption coefficient from the aethalometer data (Arnott et al., 2005). Later, when discussing real atmospheric concentrations the term LAC is used. Light scattering by aerosols has been measured at Hyytiälä since October 2006 with a TSI 3 -wavelength nephelometer but no analysis of these data has been published. We will discuss here only the time period when both the nephelometer and the aethalometer were operational, altogether 32 months.

Source area analysis based on combining in situ measurements of trace gas or particle concentrations and corresponding back trajectories has proven to be a valuable approach in atmospheric research: especially in investigating air pollution episodes, but also as a statistical method for tracing back the source areas of air masses related to high vs. low concentrations of trace gases or aerosol particles of different sizes measured at the receptor site (Stohl, 1998; Scheifinger and Kaiser, 2007; Engler, 2007). From Hyytiälä measurement site's perspective statistical trajectory methods have been used for particles of different size modes (Sogacheva et al., 2005) and trace gas concentrations (Kulmala et al., 2000; Hulkkonen, 2010; Hulkkonen et al., 2010).

The purpose of the paper is to present an analysis of the light scattering and absorption data measured at Hyytiälä, including their seasonal and diurnal variations. The particle number size distributions measured at the station will be used for modelling the scattering coefficients and also to study some basic relationships with particle size distributions and light scattering. Source areas are assessed both simply by comparing the scattering and absorption data with wind data and by applying a statistical trajectory method to identify the origins of air masses that relate to different levels of scattering and absorption in Hyytiälä.

\section{Measurements and methods}

\subsection{Sampling site}

The measurements were conducted at the SMEAR II measurement station in a cottage dedicated mainly to aerosol physical measurements (Fig. 1). In addition to these, SMEAR II has instruments for determining aerosol chemical composition, trace gas concentrations, and meteorological instruments at several locations. In this work the wind direction and speed measured at $8.4 \mathrm{~m}$ a.g.l. and at the top of the $74 \mathrm{~m}$ high mast in the immediate vicinity of the aerosol cottage were used for calculating wind roses.

The station and the aerosol physical measurements were audited by the World Calibration Centre for Aerosol Physics (WCCAP) in a field audit in May 2009. It was stated in the audit report that the possible near-by contamination sources of absorbing aerosol are the barbecue and saunas by the lake about $600 \mathrm{~m} \mathrm{~W}-\mathrm{WSW}$ of the cottage (Fig. 1) and traffic to the field station. In this paper the disturbance to aerosol optical properties due the local sources will also be discussed.

\subsection{Air sampling arrangement}

The aerosol cottage has several sample air inlets. For the aerosol optics instruments air is sampled through a Digitel $\mathrm{PM}_{10}$ inlet, mounted about $1.5 \mathrm{~m}$ above the roof of the building, lower than the surrounding tree tops. Inside the cabin air flows through stainless steel tubes $(D=25 \mathrm{~mm})$ and is split to the nephelometer and to the Aethalometer. There is no dryer in the sample line but it is inside the cabin building about $2 \mathrm{~m}$ before entering the nephelometer and the aethalometer. The cabin temperature is controlled with an air conditioner and it is $>20^{\circ} \mathrm{C}$ so the sample air warms up and relative humidity decreases. The nephelometer measures temperature both at its inlet $\left(t_{\mathrm{NEPH}, \mathrm{IN}}\right)$ and inside the sampling volume where also relative humidity $\left(\mathrm{RH}_{\mathrm{NEPH}}\right)$ is measured. When calculated from hourly-averaged data during the whole measurement period, the average and standard deviation of the temperature difference between $t_{\mathrm{NEPH}, \mathrm{IN}}$ and temperature measured outside the cabin at $8.4 \mathrm{~m}$ a.g.l. $\left(t_{8.4}\right)$ was $17 \pm 7^{\circ} \mathrm{C}$. This warming lead to decreasing of relative humidity in the nephelometer sample line and thus the average ( \pm std) $\mathrm{RH}_{\mathrm{NEPH}}$ was $32 \pm 11 \%$ in the period analyzed here. The 99th and 90th percentiles of $\mathrm{RH}_{\mathrm{NEPH}}$ were $61 \%$ and $49 \%$, respectively.

The aerosol hygroscopic growth is usually significant when RH increases above $50 \%$ and therefore the World Meteorological Organization Global Atmosphere Watch (WMO/GAW) recommends for aerosol monitoring stations to keep sample air RH at $45 \pm 5 \%$ (WMO, 2003). In the present data set about $10 \%$ of data $\mathrm{RH}_{\mathrm{NEPH}}$ was $>50 \%$. The exceedances were seasonally distributed so that in winter (December-February), spring (March-May), summer (JuneAugust), and autumn (September-November) none, 1\%, $42 \%$ and $3 \%$ of $\mathrm{RH}_{\mathrm{NEPH}}$ was $>50 \%$, respectively. In these 
exceedances the average \pm standard deviation of $\mathrm{RH}_{\mathrm{NEPH}}$ was $55 \pm 4 \%$. In the rest of the time $\mathrm{RH}_{\mathrm{NEPH}}$ was $30 \pm 9 \%$. The effect on scattering data will be discussed below.

\subsection{Scattering measurements}

Total scattering coefficients $\left(\sigma_{\mathrm{SP}}\right)$ and backscattering coefficients $\left(\sigma_{\mathrm{BSP}}\right)$ at $\lambda=450,550$ and $700 \mathrm{~nm}$ were measured with a TSI $3 \lambda$ nephelometer (Anderson et al., 1996). The 5 LPM flow to the nephelometer was provided by an external vacuum pump. The averaging time was set to $5 \mathrm{~min}$. The instrument's performance was checked during the abovementioned WCCAP field audit in May 2009 and at a European Supersites for Atmospheric Aerosol Research (EUSAAR) absorption photometer intercomparison at the Institute for Tropospheric Research, Leipzig, Germany, in July 2009. It was found to work properly apart from the relative humidity. $\mathrm{RH}_{\mathrm{NEPH}}$ has probably been overestimated based on a comparison made during the intercomparison. The linear regression of relative humidities measured with the nephelometer used in this work $\left(\mathrm{RH}_{\mathrm{SMR}}\right)$ and a similar reference nephelometer was $\mathrm{RH}_{\mathrm{SMR}}=0.95 \cdot \mathrm{RH}_{\mathrm{REF}}+13 \%$, $R^{2}=0.97$, in the $\mathrm{RH}_{\mathrm{REF}}$ range $35-55 \%$. The backscatter shutter was out of order for almost five months in November 2007 through April 2008. The raw $\sigma_{\mathrm{SP}}$ data were corrected for truncation errors by calculating first the Ångström exponents

$\alpha_{\mathrm{SP}, 12}=-\frac{\log \left(\sigma_{\mathrm{SP}, 1} / \sigma_{\mathrm{SP}, 2}\right)}{\log \left(\lambda_{1} / \lambda_{2}\right)}$

from the non-corrected scattering coefficients and then following the formulas presented by Anderson and Ogren (1998) where the tabulated factors for no cutoff at the inlet were used. The pressure and temperature of the nephelometer were used for correcting the scattering coefficients to $1000 \mathrm{mbar}$ and $0{ }^{\circ} \mathrm{C}$.

\subsection{Absorption measurements}

A $7 \lambda$ Aethalometer (AE-31) has been used at SMEAR II for measuring light absorption at $\lambda=370 \mathrm{~nm}, 470 \mathrm{~nm}, 520 \mathrm{~nm}$, $590 \mathrm{~nm}, 660 \mathrm{~nm}, 880 \mathrm{~nm}$, and $950 \mathrm{~nm}$ since 2004 . The Aethalometer reports black carbon (BC) concentrations but from these data absorption was calculated as will be discussed below. The flow was provided by the internal pump and it was set to 4.9 LPM. The averaging time was $5 \mathrm{~min}$. The instrument was checked in the WCCAP audit in May 2009 and at the EUSAAR absorption photometer intercomparison in July 2009. During the audit, when a HEPA filter was set in front of the instrument there were oscillations that could be attributed to temperature fluctuations caused by the air conditioning system. The standard deviation of the 5-minuteaveraged data during this zero test was lowest $\left(22 \mathrm{ng} \mathrm{m}^{-3}\right)$ for the UV wavelength $(370 \mathrm{~nm})$ and largest $\left(84 \mathrm{ng} \mathrm{m}^{-3}\right)$ for the near-infrared wavelength $880 \mathrm{~nm}$. For 60-minuteaverages these correspond to noise levels $6 \mathrm{ng} \mathrm{m}^{-3}$ and
$24 \mathrm{ng} \mathrm{m}^{-3}$, respectively. It can be estimated how these values correspond to noise levels of absorption coefficient $\left(\sigma_{\mathrm{AP}}\right)$ by multiplying them with the wavelength-dependent mass absorption efficiency of $14625 \mathrm{~m}^{2} \mathrm{~g}^{-1} \mathrm{~nm} / \lambda(\mathrm{nm})$, the value assumed in the firmware of the Aethalometer. The respective estimated noise levels for 60 -minute-averaged $\sigma_{\mathrm{AP}}$ were 0.25 and $0.46 \mathrm{Mm}^{-1}$.

The above-mentioned way for calculating $\sigma_{\mathrm{AP}}$ would be easy but it has been shown that the relationship between the $\mathrm{BC}$ reported by the Aethalometer and $\sigma_{\mathrm{AP}}$ is not linear. It depends on several parameters, the most important of which are the loading of the filter and contribution of scattering aerosol. Several algorithms for calculating $\sigma_{\mathrm{AP}}$ from Aethalometer data have been presented, e.g., Weingartner et al. (2003), Arnott et al. (2005), and Collaud-Coen et al. (2010). The algorithm we presented earlier (Virkkula et al., 2007) was developed for making the $\mathrm{BC}$ data continuous across filter-spot changes but it was not compared with any absolute absorption measurements. We have here chosen to use the Arnott et al. (2005) algorithm, since it has background in multiple scattering theory that was used to obtain analytically a filterloading and scattering correction function. In that algorithm absorption coefficients at time step $n\left(\sigma_{P_{\mathrm{AP}}, n}\right)$ are calculated from:

$\sigma_{\mathrm{AP}, n}=\frac{\mathrm{SGBC}_{n}-s \sigma_{\mathrm{SP}, n}}{M} \sqrt{1+\frac{\left(\frac{Q d t}{A}\right) \sum_{i=1}^{n-1} \sigma_{\mathrm{AP}, i}}{\tau_{\mathrm{a}, f x}}}$

where SG is the wavelength-dependent $\mathrm{BC}$ mass absorption efficiency assumed by the manufacturer $\left(14625 \mathrm{~m}^{2} \mathrm{~g}^{-1} \mathrm{~nm} / \lambda(\mathrm{nm})\right), \quad \mathrm{BC}_{n}$ the black carbon concentration reported by the aethalometer at time step $n$ after the start of sampling on a new filter spot, $\sigma_{\mathrm{SP}, n}$ the scattering coefficient measured simultaneously with a nephelometer, $s$ the scattering correction factor (denoted as $\alpha$ in the original article, but here $s$ is used to avoid confusion with $\alpha_{\mathrm{SP}}$ and $\left.\alpha_{\mathrm{AP}}\right) Q$ the flow rate, $A$ the spot size, and $\sigma_{\mathrm{AP}, i}$ the absorption coefficient at time step $i, \tau_{\mathrm{a}, f x}$ the filter absorption optical depth for the filter fraction that has particles embedded in it, and $M$ a multiple scattering enhancement factor. Arnott et al. (2005) report the values for $M, s, \tau_{\mathrm{a}, f x}$ and state that values $M=3.688$ and $\tau_{\mathrm{a}, f x}=0.2338$ would be more appropriate for ambient measurements at $521 \mathrm{~nm}$. Chow et al. (2009) used these values and assumed that the wavelength dependency of these factors remains similar, but did not present any exact values for the constants. We have used here the same approach. Fitting a power function to the values presented by Arnott et al. (2005) yields $\tau_{\mathrm{a}, f x}$ $(\lambda)=23.76 \lambda^{-0.754}$ and $M(\lambda)=0.656 \lambda^{0.181}$, where $\lambda$ is wavelength in $\mathrm{nm}$. The $\tau_{\mathrm{a}, f x}$ and $M$ values were calculated for the aethalometer wavelengths using these relationships, the scattering correction factors of Arnott et al. (2005) were used as such. 
In the comparison by Collaud-Coen et al. (2010) the slope of the absorption coefficient calculated from Aethalometer data with the Arnott algorithm and that measured with a Multi-Angle Absorption Photometer (MAAP) was 1.77 and 2.48 for data collected at Cabauw and Hohenpeissenberg and very high, 15.2 at Mace Head but this station is an outlier because of its high sea salt concentrations. However, in their data analysis the Arnott et al. (2005) values of $M$ and $\tau_{\mathrm{a}, f x}$ were used as such. We have here used the values Arnott et al. (2005) recommended for ambient measurements. In our data the average ratio of $\sigma_{\mathrm{AP}}$ calculated with the Arnott et al. (2005) ambient $M$ and $\tau_{\mathrm{a}, f x}$ and the laboratory $M$ and $\tau_{\mathrm{a}, f x}$ values was $0.50 \pm 0.03$, which would bring also the Cabauw and Hohenpeissenberg Aethalometer vs. MAAP slopes clearly closer to one. Algorithm intercomparisons were not conducted in this work.

The scattering coefficients required in the formula were calculated by interpolating and extrapolating the measured and truncation-corrected $\sigma_{\mathrm{SP}}$ at the nephelometer wavelengths $\lambda_{\mathrm{NEPH}}(450,550$, and $700 \mathrm{~nm})$ to the aethalometer wavelengths $\lambda_{\mathrm{AE}}$ from $\sigma \mathrm{SP}\left(\lambda_{\mathrm{AEx}}\right)=$ $\sigma_{\mathrm{SP}}\left(\lambda_{\mathrm{NEPH}}\right)\left(\lambda_{\mathrm{NEPH}} / \lambda_{\mathrm{AE}}\right)^{\alpha}$ which assumes the Angström exponent is constant over the wavelength range.

After calculating $\sigma_{\mathrm{AP}}$ the noise of the data was estimated. The filter test discussed above was conducted during the WCCAP only so it cannot be definitely be said how the noise was at other times. However, some estimate of the noise can be calculated by analyzing periods with low absorption coefficients. This was done for periods when $\sigma_{\mathrm{AP}}<1 \mathrm{Mm}^{-1}$ continuously for more than three hours. The maximum difference $\left(\Delta_{\max } \sigma_{\mathrm{AP}}(3 \mathrm{~h})=\sigma_{\mathrm{AP}}(\max 3 \mathrm{~h})-\sigma_{\mathrm{AP}}(\min 3 \mathrm{~h})\right)$ within each continuous period of $3 \mathrm{~h}$ was calculated. During the whole period analyzed here the average ( \pm standard deviation) $\Delta_{\max } \sigma_{\mathrm{AP}}(3 \mathrm{~h})$ was $0.16 \pm 0.13 \mathrm{Mm}^{-1}$ at $\lambda=550 \mathrm{~nm}$. The respective averages over winter, spring, summer, and autumn were $0.14 \pm 0.13 \mathrm{Mm}^{-1}, 0.16 \pm 0.12 \mathrm{Mm}^{-1}$, $0.18 \pm 0.13 \mathrm{Mm}^{-1}, 0.14 \pm 0.14 \mathrm{Mm}^{-1}$. The noise was the largest in summer which supports the interpretation that a significant contribution to the noise came from the air conditioning system.

\subsection{Size distribution measurements}

Particle number size distributions were measured with a custom-made Twin-DMPS (TDMPS) system in the size range 3-1000 nm (Aalto et al., 2001) and a TSI aerodynamic particle sizer APS in the aerodynamic diameter size range $0.53-20 \mu \mathrm{m}$. In the overlapping range of the TDMPS and the APS the number concentrations from the TDMPS were used up to $700 \mathrm{~nm}$. The TDMPS consists of a short Hauke-type DMA with a TSI Model 3025 CPC as the particle counter and a medium-size Hauke-type DMA with a TSI Model 3020 CPC as the particle counter. During the audit in May 2009 the TMDPS was run in parallel to the travelling standard SMPS of the WCCAP. Average particle number size distribu- tions for the whole time period were in good agreement. The sample air of the TDMPS is not dried but the sheath air of both DMAs is dried by silica gel dryers. In addition, inside the aerosol cottage the sample lines get heated by the room air compared to the outdoor air, as discussed above, and thus the sample air relative humidity is clearly lower than in the outdoor air even before mixing with the dried sheath air. The temperature and relative humidity of both sheath air flows are measured. The average \pm standard deviation of the sheath air temperature and $\mathrm{RH}$ of the two DMPS's were $22.4 \pm 2.3^{\circ} \mathrm{C}$ and $16 \pm 7 \%$, respectively, in the period discussed in this paper.

An Aerodynamic Particle Sizer (TSI Model 3321) is used to measure the number size distribution of particles larger than $0.53 \mu \mathrm{m}$. The inlet of the instrument is vertical. The inlet is heated to a temperature of about $10^{\circ}$ above ambient. The APS measures concentration of particles at the aerodynamic diameter $D_{\text {a }}$ whereas the DMPS at the mobility diameter $D_{\mathrm{m}}$. For spherical particles, $D_{\mathrm{m}}$ is equal to the geometric diameter $D_{\mathrm{p}}$ (e.g., DeCarlo et al., 2004). To combine size distributions measured with the two instruments and so to obtain continuous size distributions the geometric diameters were calculated from the aerodynamic diameters of the APS data. In principle this is calculated from

$D_{\mathrm{p}}=\sqrt{\frac{\rho_{0}}{\rho}} \sqrt{\frac{C_{\mathrm{C}}\left(D_{\mathrm{a}}\right)}{C_{\mathrm{C}}\left(D_{\mathrm{p}}\right)}} D_{\mathrm{a}}$

where $C_{\mathrm{C}}\left(D_{\mathrm{P}}\right)$ is the slip correction factor, $\rho_{0}$ the unit density $1 \mathrm{~g} \mathrm{~cm}^{-3}$, and $\rho$ the particle density. $C_{\mathrm{C}}$ is close to unity in the size range $D_{\mathrm{p}}>700 \mathrm{~nm}$ so in practice the geometric diameters were calculated simply from $D_{\mathrm{p}}=D_{\mathrm{a}} \rho^{-1 / 2}$.

There are two independent estimates of Hyytiälä aerosol density. Saarikoski et al. (2005) measured the chemical composition of the particles collected with a low pressure impactor and obtained the density of $1.49 \pm 0.03 \mathrm{~g} \mathrm{~cm}^{-3}$ for submicron particles. From gravimetric analyses they found that the average density was $1.66 \pm 0.13$. Kannosto et al. (2008) used a combination of an Electric Low Pressure Impactor (ELPI), a DMPS and an APS and found that the density of accumulation mode particles at Hyytiälä varied from 1.1 to $2 \mathrm{~g} \mathrm{~cm}^{-3}$, with the average of $1.5 \mathrm{~g} \mathrm{~cm}^{-3}$. In this work the value $\rho=1.5 \mathrm{~g} \mathrm{~cm}^{-3}$ was used because it is close to the averages presented in both of the above mentioned studies.

\subsection{Quantities derived from scattering and absorption coefficients}

The aerosol properties that vary as a function of particle amount, such as $\sigma_{\mathrm{SP}}$ and $\sigma_{\mathrm{AP}}$, particle number concentration are called extensive, while properties that relate to the nature of the aerosol are called intensive properties (Ogren, 1995). The intensive optical properties calculated here are the Ångström exponent, the hemispheric backscatter fraction and the single-scattering albedo. 
The wavelength dependency of scattering is represented by the Ångström exponent of scattering, $\alpha_{\mathrm{SP}}$. If $\sigma_{\mathrm{SP}}$ are available at several wavelengths, $\alpha_{\mathrm{SP}}$ can be calculated for the whole wavelength range by taking logarithm of scattering coefficients and the respective wavelengths and fitting the data line to the line

$\ln \left(\sigma_{\mathrm{SP}, \lambda}\right)=-\alpha_{\mathrm{SP}} \ln (\lambda)+C$

where $C$ is a constant irrelevant in this work. The $\alpha_{\mathrm{SP}}$ presented in the subsequent analyses was calculated over the nephelometer wavelength range $450-700 \mathrm{~nm}$. The relationships between $\alpha_{\mathrm{SP}}$ and particle size distributions will be discussed below.

The wavelength dependency of absorption yields information on the absorbing material. For pure LAC particles $\sigma_{\mathrm{AP}}$ is approximately inversely proportional to $\lambda$, in other words the Ångström exponent of absorption $\alpha_{\mathrm{AP}} \approx 1$ over the visible band (e.g., Van de Hulst, 1957; Schnaiter et al., 2003) but for aerosol containing also organics $\alpha_{\mathrm{AP}}$ is higher (e.g., Kirchstetter et al., 2004; Schnaiter et al., 2006; Bergstrom et al., 2007; Lewis et al., 2008). The Ångström exponent of absorption $\left(\alpha_{\mathrm{AP}}\right)$ was calculated over the visible-to-NIR wavelength range $470-950 \mathrm{~nm}$ with the same approach as $\alpha_{\mathrm{SP}}$, i.e. by fitting the data to $\ln \left(\sigma_{\mathrm{AP}, \lambda}\right)=-\alpha_{\mathrm{AP}} \ln (\lambda)+C$.

The absorption coefficients at the Aethalometer wavelengths were interpolated logarithmically to the nephelometer wavelengths to calculate the single-scattering albedo

$\omega_{0}=\frac{\sigma_{\mathrm{SP}}}{\sigma_{\mathrm{SP}}+\sigma_{\mathrm{AP}}}$

which is a measure of the darkness of aerosols. At low $\omega_{0}$ values aerosols heat the atmosphere and at high values cool it, depending also on $b$, and other parameters (e.g., Haywood and Shine, 1995). $\omega_{0}$ is approximately 0.3 for pure LAC particles (e.g., Mikhailov et al., 2006) and 1 for purely scattering aerosol, for example ammonium sulfate. It also varies as a function of wavelength but below $\omega_{0}$ only at $\lambda=550 \mathrm{~nm}$ is discussed.

The hemispheric backscatter ratio

$b=\frac{\sigma_{\mathrm{BSP}}}{\sigma_{\mathrm{SP}}}$

is a measure related to the angular distribution of light scattered by aerosol particles. From $b$ it is possible to estimate the average upscatter fraction $\beta$ and aerosol asymmetry parameter that are key properties controlling the aerosol direct radiative forcing (e.g., Andrews et al., 2006). The larger $b$ is, the more aerosols scatter light to space and cool the atmosphere - or, heat it less if the aerosol is so dark that it heats the atmosphere. This can be shown by using the formula for aerosol forcing efficiency $\Delta F / \delta$, i.e., aerosol forcing per unit optical depth $(\delta)$ :

$$
\begin{aligned}
& \frac{\Delta F}{\delta}=-D S_{0} T_{\mathrm{at}}^{2}\left(1-A_{\mathrm{c}}\right) \omega_{0} \beta \\
& \left\{\left(1-R_{\mathrm{s}}\right)^{2}-\left(\frac{2 R_{\mathrm{s}}}{\beta}\right)\left[\left(\frac{1}{\omega_{0}}\right)-1\right]\right\}
\end{aligned}
$$

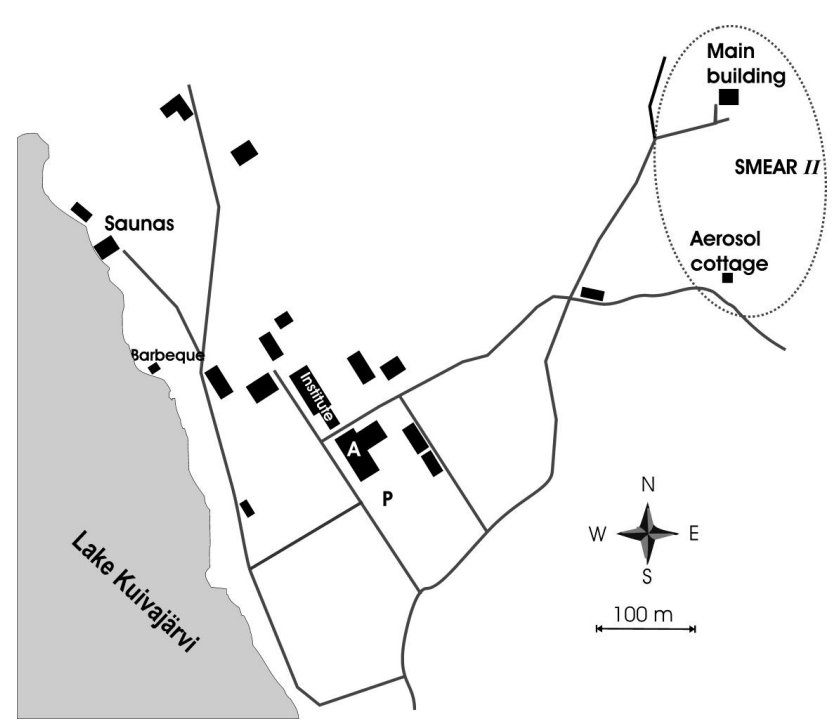

Fig. 1. A schematic map of the Hyytiälä forestry field station. The measurements were conducted in the aerosol cottage that is part of the SMEAR II station.

where $D$ is the fractional day length, $S_{0}$ is the solar constant, $T_{\text {at }}$ is the atmospheric transmission, $A_{\mathrm{c}}$ is the fractional cloud amount, $R_{\mathrm{S}}$ is the surface reflectance, and $\beta$ is the average upscatter fraction calculated from $b$. If the non-aerosol-related factors are kept constant and if it is assumed that $\beta$ has no zenith angle dependence this formula can be used for assessing the intrinsic radiative forcing efficiency by aerosols (e.g., Sheridan and Ogren, 1999; Delene and Ogren, 2002). The constants used were $D=0.5$, $S_{0}=1370 \mathrm{~W} \mathrm{~m}^{-2}, T_{\mathrm{at}}=0.76, A_{\mathrm{c}}=0.6$, and $R_{\mathrm{S}}=0.15$ as suggested by Haywood and Shine (1995) and $\beta$ was calculated from $\beta=0.817+1.8495 b-2.9682 b^{2}$ (Delene and Ogren, 2002).

It is generally recommended to compare measured $\sigma_{\mathrm{SP}}$ with that calculated from size distribution measurements to find how close a local optical closure can be achieved. The agreement of scattering and size distribution data was assessed by modelling scattering coefficients at the nephelometer wavelengths from

$\sigma_{\mathrm{SP}}(\lambda)=\int Q_{\mathrm{SP}}\left(\lambda, D_{\mathrm{p}}, m\right) \frac{\pi D_{\mathrm{p}}^{2}}{4} \frac{d N}{d \log D_{\mathrm{p}}} d D_{\mathrm{p}}$

where $Q_{\mathrm{SP}}\left(\lambda, D_{\mathrm{p}}, m\right)$ is the scattering efficiency of particles with diameter $D_{\mathrm{p}}$ and the complex refractive index $m=$ $m_{\mathrm{r}}+m_{\mathrm{i}} i$ at wavelength $\lambda$. The scattering efficiencies were calculated using the Mie code by Barber and Hill (1990).

Similarly also absorption coefficients can be calculated. An estimate of the effective complex refractive index can be obtained by an iterative approach, by matching the measured and the modelled $\sigma_{\mathrm{SP}}$ and $\sigma_{\mathrm{AP}}$. The code used by Virkkula et al. (2006) was modified in this work to take also the imaginary refractive index into account. The iteration 


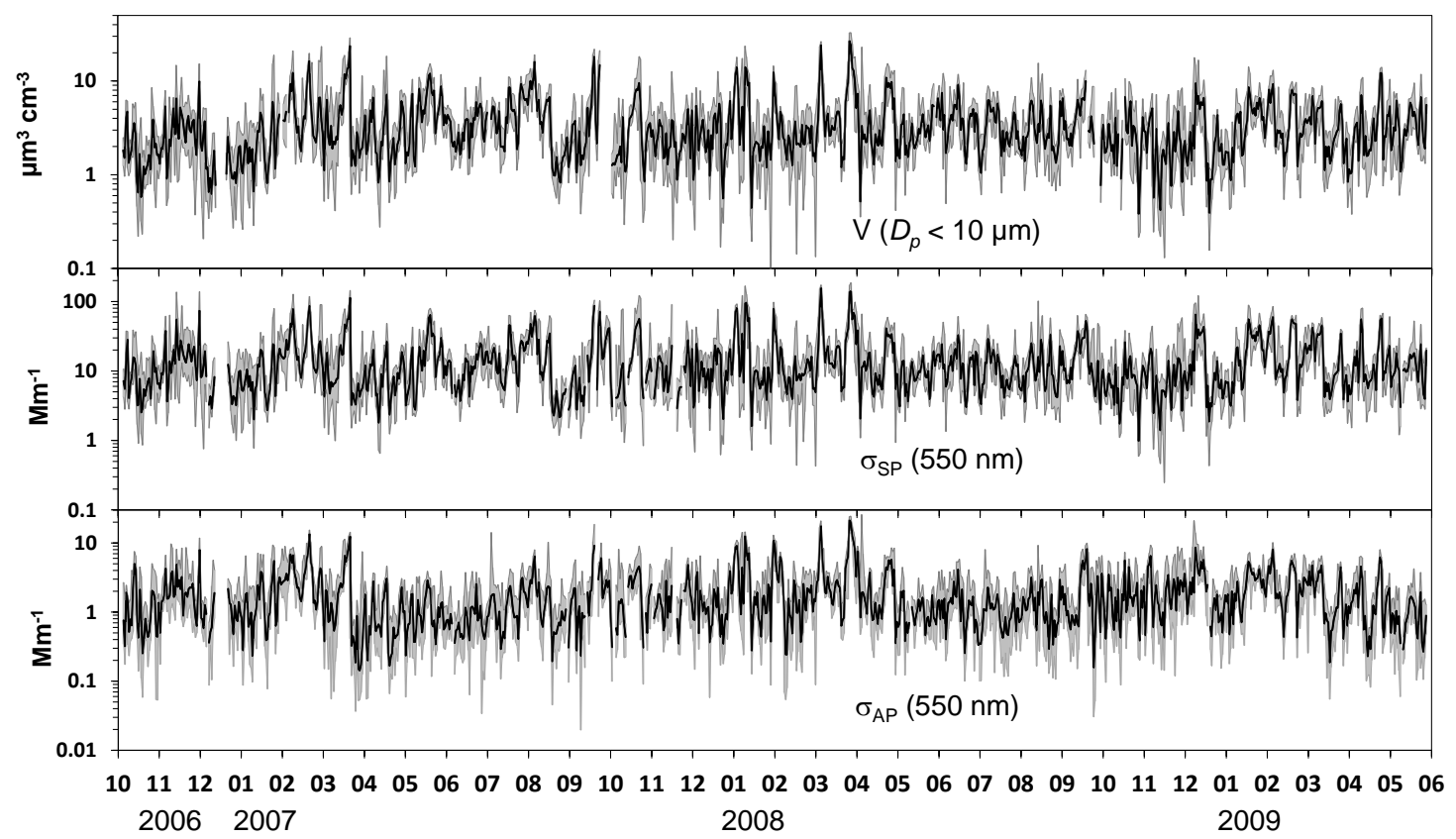

Fig. 2. Particle volume concentration, scattering coefficient $\left(\sigma_{\mathrm{SP}}\right)$, and absorption coefficient $\left(\sigma_{\mathrm{AP}}\right)$ at $\lambda=550 \mathrm{~nm}$ measured at SMEAR II in 13 October 2006-31 May 2009. Black line: daily median; the gray shaded area: the 95 percent range (2.5th and 97.5 th percentiles) of the hourly-averaged data in each day.

Table 1. Statistical summary of aerosol optics data measured at Hyytiälä SMEAR II station in 13 October $2006-31$ may 2009 . $N / N_{\text {tot }}$, $\%$ : fraction of total number of hours $\left(N_{\text {tot }}=23081\right)$. Scattering coefficients $\left(\sigma_{\mathrm{SP}}\right)$ and absorption coefficients $\left(\sigma_{\mathrm{AP}}\right)$ in Mm ${ }^{-1}$ corrected to STP (1013 mbar, $273.15 \mathrm{~K})$, backscatter fractions $(b)$, Ångström exponents of scattering and absorption $\left(\alpha_{\mathrm{SP}}, \alpha_{\mathrm{AP}}\right)$, single-scattering albedo $\left(\omega_{0}\right)$, real refractive index $\left(m_{\mathrm{r}}\right)$ and imaginary refractive index $\left(m_{\mathrm{i}}\right)$ are unitless, aerosol forcing efficiency $\Delta F / \delta$ in $\mathrm{W} \mathrm{m}^{-2}$.

\begin{tabular}{llrrrrrr}
\hline & & & \multicolumn{5}{c}{ Percentiles } \\
\cline { 4 - 8 } & $N / N_{\text {tot }}, \%$ & AVE \pm STD & 1 & 10 & 50 & 90 & 99 \\
\hline$\sigma_{\mathrm{SP}}(450 \mathrm{~nm})$ & 97 & $25 \pm 27$ & 2.2 & 5.4 & 17 & 56 & 132 \\
$\sigma_{\mathrm{SP}}(550 \mathrm{~nm})$ & 97 & $18 \pm 20$ & 1.6 & 4.1 & 12 & 40 & 98 \\
$\sigma_{\mathrm{SP}}(700 \mathrm{~nm})$ & 97 & $12 \pm 13$ & 1.1 & 2.8 & 8 & 25 & 63 \\
$b(450 \mathrm{~nm})$ & 83 & $0.13 \pm 0.03$ & 0.08 & 0.10 & 0.12 & 0.16 & 0.21 \\
$b(550 \mathrm{~nm})$ & 83 & $0.14 \pm 0.03$ & 0.09 & 0.11 & 0.14 & 0.18 & 0.22 \\
$b(700 \mathrm{~nm})$ & 83 & $0.19 \pm 0.04$ & 0.11 & 0.14 & 0.19 & 0.24 & 0.31 \\
$\sigma_{\mathrm{AP}}(450 \mathrm{~nm})$ & 97 & $3.1 \pm 3.4$ & 0.2 & 0.6 & 2.1 & 6.7 & 17 \\
$\sigma_{\mathrm{AP}}(550 \mathrm{~nm})$ & 97 & $2.2 \pm 2.4$ & 0.1 & 0.4 & 1.5 & 4.8 & 12 \\
$\sigma_{\mathrm{AP}}(700 \mathrm{~nm})$ & 97 & $1.7 \pm 1.8$ & 0.1 & 0.3 & 1.1 & 3.7 & 8.9 \\
$\alpha_{\mathrm{SP}}$ & 97 & $1.7 \pm 0.5$ & 0.4 & 0.9 & 1.8 & 2.2 & 2.5 \\
$\alpha_{\mathrm{AP}}$ & $84^{1}$ & $1.4 \pm 0.3$ & 0.9 & 1.1 & 1.4 & 1.6 & 2.3 \\
$\omega_{0}(550 \mathrm{~nm})$ & 97 & $0.88 \pm 0.07$ & 0.64 & 0.79 & 0.89 & 0.95 & 0.98 \\
$m_{\mathrm{r}}$ & $94^{2}$ & $1.517 \pm 0.057$ & 1.363 & 1.453 & 1.515 & 1.588 & 1.659 \\
$m_{\mathrm{i}}$ & $94^{2}$ & $0.019 \pm 0.015$ & 0.0026 & 0.0059 & 0.016 & 0.035 & 0.076 \\
$\Delta F / \delta$ & 83 & $-23.0 \pm 5.0$ & -7.7 & -16.9 & -23.4 & -28.8 & -32.1 \\
\hline
\end{tabular}

1 The fraction of data used for calculating $\alpha_{\mathrm{AP}}$ is smaller than that of $\sigma_{\mathrm{AP}}$ because only those data were used where $\sigma_{\mathrm{AP}}(550 \mathrm{~nm})$ was $>0.5 \mathrm{Mm}{ }^{-1}$.

2 The fraction of data used for calculating the refractive indices is smaller than that of $\sigma_{\mathrm{SP}}$ and $\sigma_{\mathrm{AP}}$ because it also takes breaks in size distribution data into account.

was started with an initial $m$ value of $1.45+0.002 i$. First the real refractive index was either increased or decreased at steps of 0.0001 until measured and modeled scattering agreed within $\pm 1 \%$. After that the real part was kept constant and the imaginary refractive index was varied similarly until the measured and modeled absorption agreed to within 


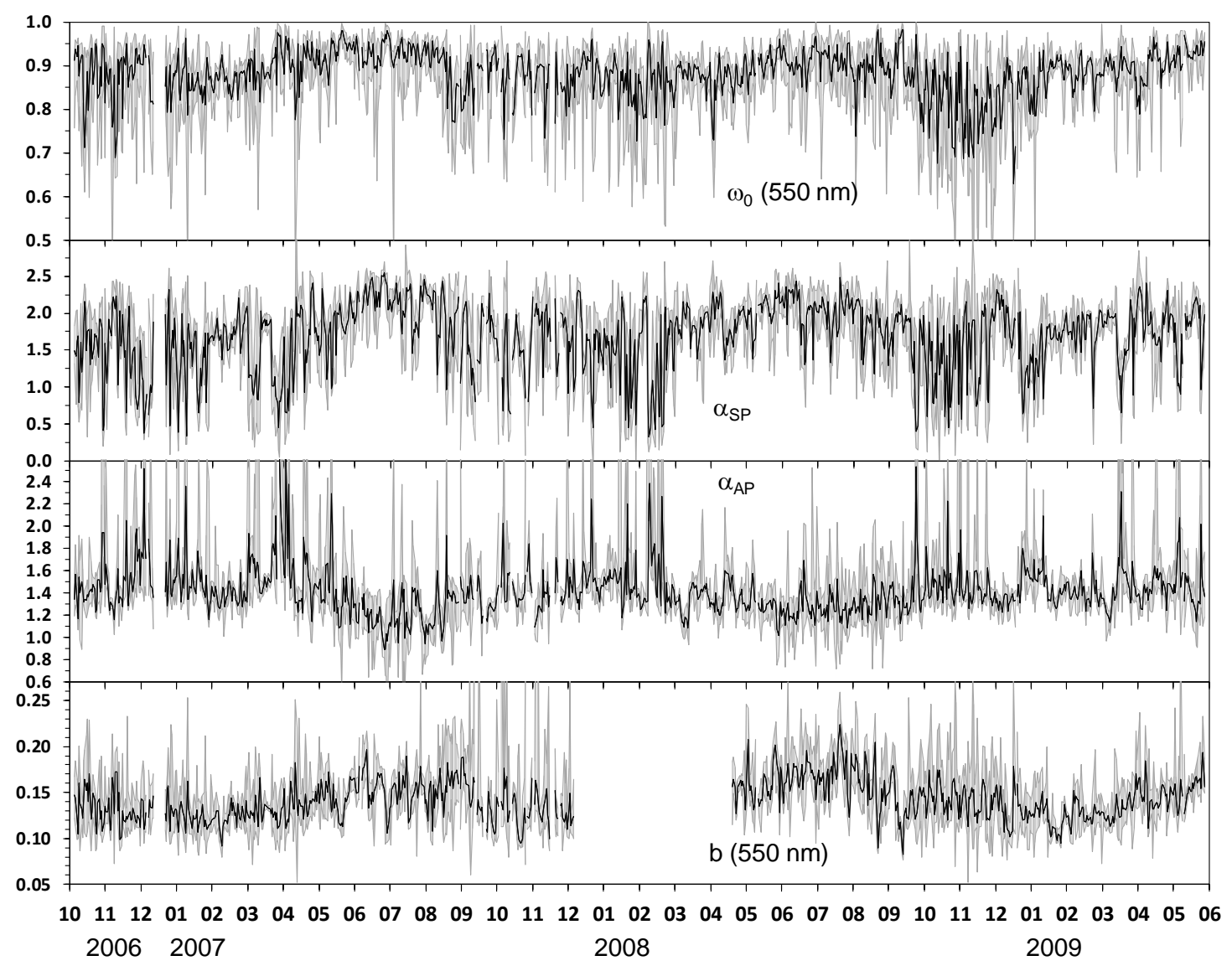

Fig. 3. Selected intensive aerosol properties at SMEAR II in October 2006-May 2009: Single-scattering albedo $\omega_{0}(\lambda=550 \mathrm{~nm})$, Ångström exponent of absorption, $\alpha_{\mathrm{AP}}(\lambda=470-950 \mathrm{~nm})$, Ångström exponent of scattering $\alpha_{\mathrm{SP}}(\lambda=450-700 \mathrm{~nm})$, and backscatter fraction, $b$ ( $\lambda=$ $550 \mathrm{~nm})$. Black line: daily median; the gray shaded area: the 95 percent range (2.5th and 97.5 th percentiles) of the hourly-averaged data in each day.

$\pm 1 \%$. Then the modeled scattering had to be reiterated and then again absorption. This was repeated until both absorption and scattering were within the $1 \%$ limits.. The iteration converged for both real and imaginary refactive index in $97 \%$ of those hourly-averaged data when both scattering, absorption and size distributions were available. For the remaining $3 \%$ no solution was not obtained, due either to aerosol optics or the size distribution data. Here the results for $\lambda=550 \mathrm{~nm}$ will be presented. A more detailed analysis of the iterative process is out of the scope of the present paper. It has to be kept in mind that this is an effective refractive index of the whole size range, so it is a strong simplification. In reality the absorbing particles have different size distribution than the scattering particles and so the real and imaginary refractive indices also have different size distributions.

\section{Results and discussion}

\subsection{Overview of aerosol optical properties}

The daily medians of the integrated aerosol volume concentration $V$ for particles smaller than $10 \mu \mathrm{m}$ in diameter, total scattering coefficient $\sigma_{\mathrm{SP}}$ and absorption coefficient $\sigma_{\mathrm{AP}}$, both at $\lambda=550 \mathrm{~nm}$ are plotted in Fig. 2 . The time series have some common features. $V$ and $\sigma_{\mathrm{SP}}$ follow each other closely, somewhat better than $\sigma_{\mathrm{AP}}$, but all have peak values in the same days. Another common feature is that there is not a very strong seasonal variation. The daily medians vary approximately one order of magnitude, and the $95 \%$ range of hourly averages close to two orders of magnitude. There were four days when the daily median $\sigma_{\mathrm{SP}}$ at $\lambda=550 \mathrm{~nm}$ exceeded $100 \mathrm{Mm}^{-1}$, and the highest hourly averages were close to $200 \mathrm{Mm}^{-1}$.

The respective values of the intensive state parameters $\omega_{0}$, $\alpha_{\mathrm{AP}}, \alpha_{\mathrm{SP}}$, and $b$ are plotted in Fig. 3. They all have interesting features. First of all, they all have clearer seasonal variations than $\sigma_{\mathrm{SP}}$ and $\sigma_{\mathrm{AP}}$. The lowest 2.5th percentile of $\omega_{0}$ 


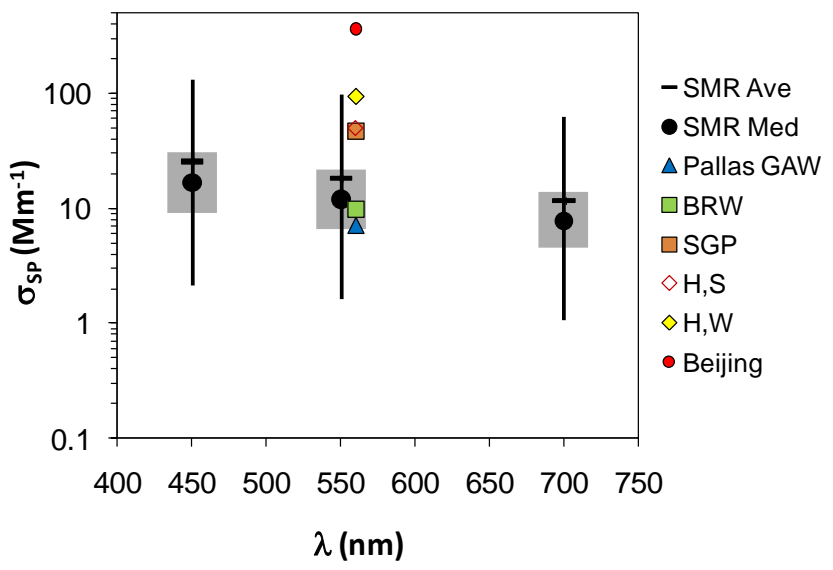

Fig. 4. Averages, medians, 1st, 25th, 75th, and 99th percentiles of hourly-averaged $\sigma_{\mathrm{SP}}$ at Hyytiälä (SMR) in October 2006May 2009. For comparison the average $\sigma_{\mathrm{SP}}(550 \mathrm{~nm})$ measured at the Pallas GAW station in Finnish Lapland (Aaltonen et al., 2006), Barrow in Alaska (BRW), Southern Great Plains in Oklahoma (SGP) (Delene and Ogren, 2002), Hungarian plain in summer (H, S) and in winter (H, W) (Mészáros et al., 1998) and in Beijing, China (Garland et al., 2009) are presented.

frequently drops below 0.7 , espcially in winter indicating that in these cases a significant contribution to the aerosol is LAC. The daily median $\omega_{0}$, on the other hand, is close to 0.9 in summer but in winter there are several days when it drops below 0.8 . The time series shows that there seems to be a negative correlation between between $\omega_{0}$ and $\alpha_{\mathrm{AP}}$ which means that when aerosol is darkest the shorter wavelengths absorb more light compared to longer wavelengths than when $\omega_{0}$ is $>0.9$. According to the above-mentioned references this suggests that the darkest aerosol contained more light absorbing organics than the lighter aerosols. The $\omega_{0}$ and $\alpha_{\mathrm{SP}}$ seem to be positively correlated which is not that straightforward to explain because low $\alpha_{\mathrm{SP}}$ is generally assumed to be associated with domination of large particles whereas the diameter of fresh LAC particles is typically $\sim 100 \mathrm{~nm}$. The backscatter fraction $b$ behaves more independently but also it has maximum daily medians in summer months. $b$ is inversely related to particle size. Therefore the positive correlation of $b$ and $\alpha_{\text {SP }}$ would support the traditional interpretation of the inverse relationship between particle size and $\alpha_{\mathrm{SP}}$.

The basic statistical summary of extensive and intensive aerosol properties are presented in Table 1 and Fig. 4. To put the data in some global perspective the scattering coefficients measured also at five other sites are plotted in Fig. 4: the 3year (2001-2004) average $\sigma_{\mathrm{SP}}(550 \mathrm{~nm}) 7.1 \mathrm{Mm}^{-1}$ at the Pallas GAW station in Finnish Lapland (Aaltonen et al., 2006), the summer and winter averages $50 \mathrm{Mm}^{-1}$ and $93 \mathrm{Mm}^{-1}$, respectively, at a Hungarian background site (Mészáros et al., $1998)$, the 25 -month average $\sigma_{\mathrm{SP}}(550 \mathrm{~nm}) 9.8 \mathrm{Mm}^{-1}$ in Barrow Alaska, the $34-$ month average $\sigma_{\mathrm{SP}}(550 \mathrm{~nm}) 46.9 \mathrm{Mm}^{-1}$ in the Southern Great Plains station (SGP), Oklahoma (De-

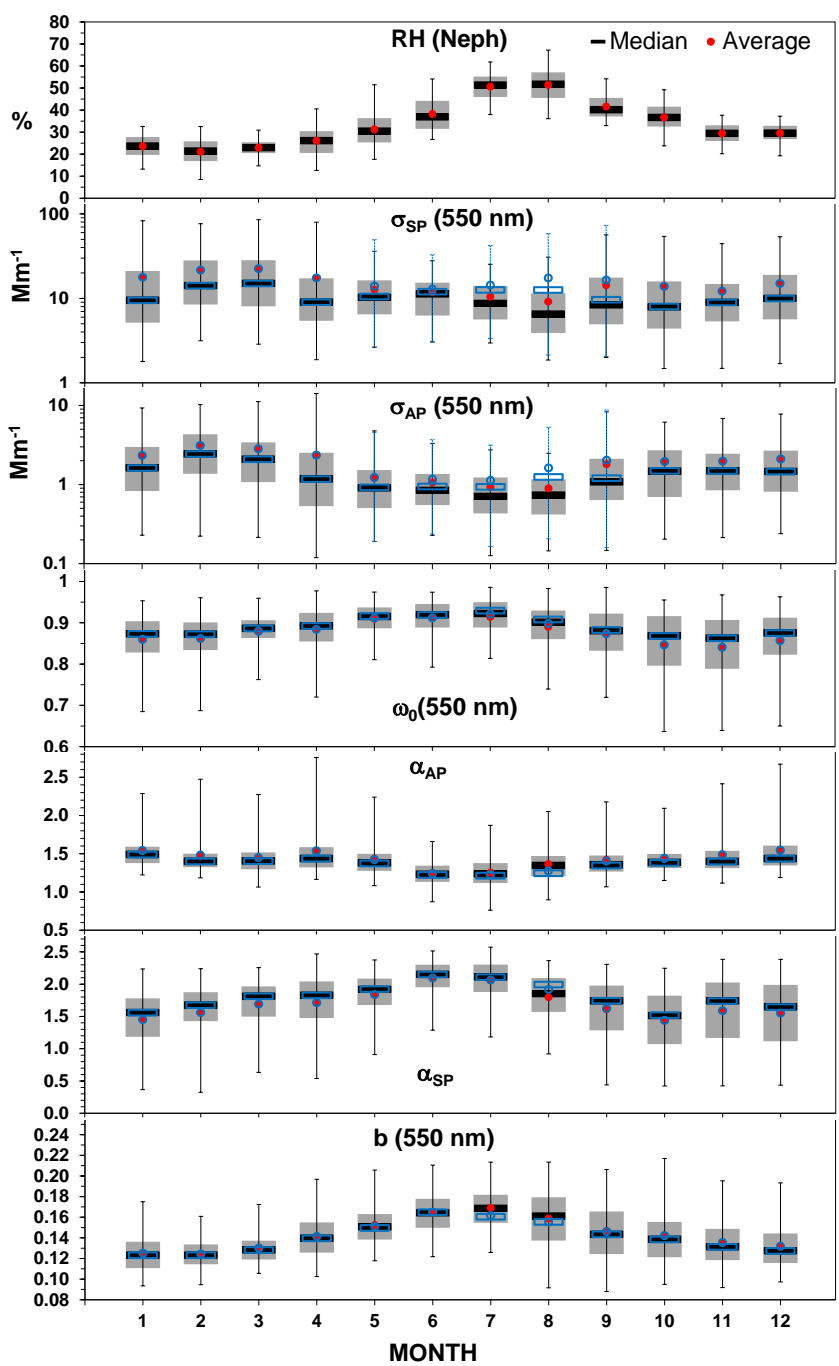

Fig. 5. Seasonal cycle selected extensive and intensive aerosol optical properties: scattering coefficient $\left(\sigma_{\mathrm{SP}}\right)$ and absorption coefficient $\left(\sigma_{\mathrm{AP}}\right)$ single-scattering albedo $\left(\omega_{0}\right)$, Ångström exponent of absorption $\left(\alpha_{\mathrm{AP}}\right)$ and scattering $\left(\alpha_{\mathrm{SP}}\right)$, and the backscatter fraction $(b)$, and relative humidity measured in the nephelometer sample volume $\left(\mathrm{RH}_{\mathrm{Neph}}\right)$ in 13 October 2006-31 May 2009. The grey box represents the 25 th to 75 th percentile range and the thin bars the 95 percent range ( 2.5 th and 97.5 th percentiles) of the hourlyaveraged data in each month. The black line and the red circle for the optical properties represent the mean and median of those data where $\mathrm{RH}_{\mathrm{NEPH}}<50 \%$ and the respective blue symbols all data without $\mathrm{RH}$ filtering. For $\mathrm{RH}_{\mathrm{NEPH}}$ all data were used for the statistics.

lene and Ogren, 2002), and the 1-month average $\sigma_{\mathrm{SP}}(550 \mathrm{~nm})$ $361 \mathrm{Mm}^{-1}$ in Beijing, China (Garland et al., 2009). These comparison stations were selected since Pallas GAW station is in Northern Finland, Barrow is a comparable Arctic site, the Hungarian site represents Central European continental aerosol, SGP is representative of North American continental aerosol and Beijing is an example of a highly polluted site. 

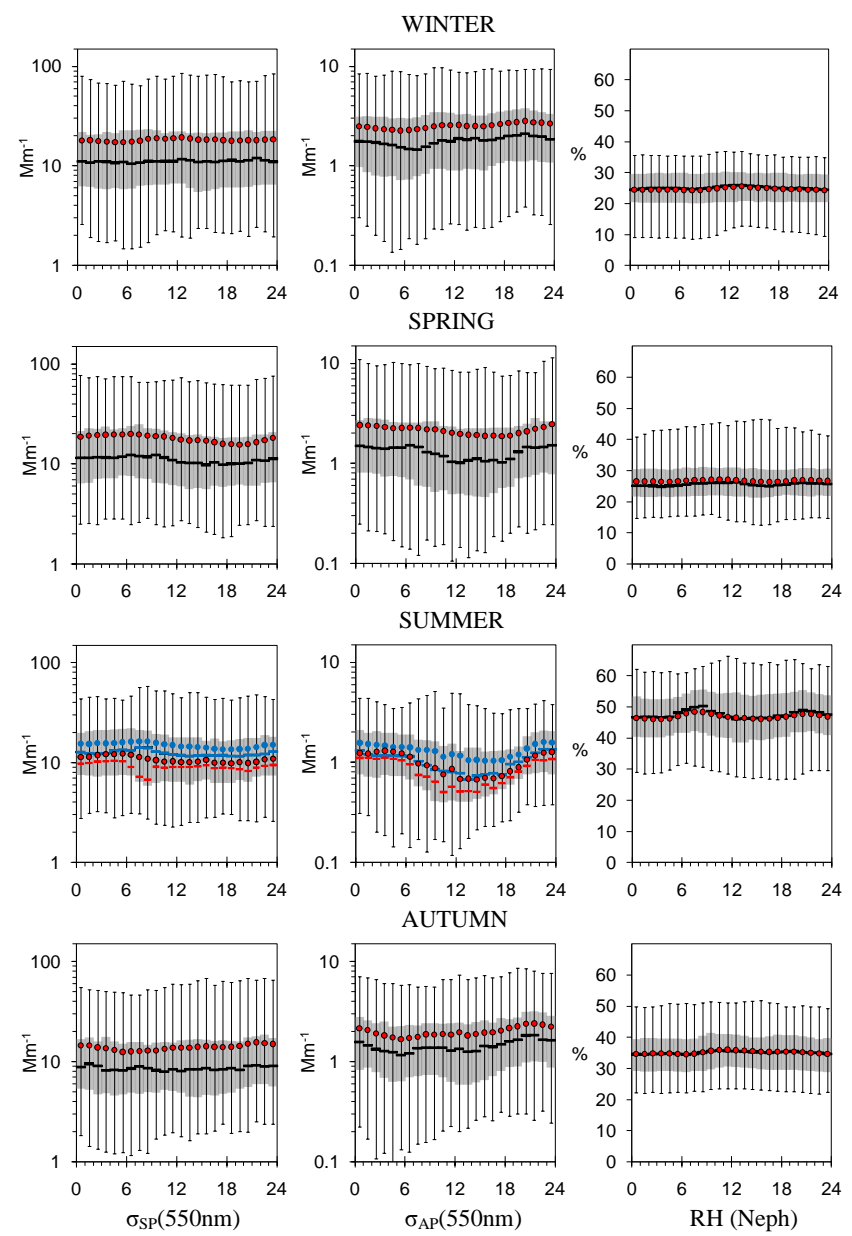

Fig. 6. Diurnal cycle of scattering coefficient $\left(\sigma_{\mathrm{SP}}\right)$, absorption coefficient $\left(\sigma_{\mathrm{AP}}\right)$, and relative humidity measured in the nephelometer sample volume $\left(\mathrm{RH}_{\mathrm{Neph}}\right)$ in four seasons in 13 October 200631 May 2009. Red dot: average; black line: median; grey bar: 25th to 75th percentiles; thin error bar: 2.5 th to 97.5 th percentiles. For the summer $\sigma_{\mathrm{SP}}$ and $\sigma_{\mathrm{AP}}$ data the red symbols represent the mean and median of those data where $\mathrm{RH}_{\mathrm{NEPH}}<50 \%$ and the respective blue symbols all data without $\mathrm{RH}$ filtering. For $\mathrm{RH}_{\mathrm{NEPH}}$ all data were used for the statistics. In other seasons all data were used.

The average $\sigma_{\mathrm{SP}}$ at Hyytiälä $18 \mathrm{Mm}^{-1}$ is more than twice as much as at the Pallas GAW station. This may be attributed both to anthropogenic and biogenic sources since Hyytiälä is closer to urban areas in Finland, Central and Eastern Europe and it is in the middle of a forest whereas the Pallas station is on top of a treeless, barren hill far from significant anthropogenic sources. In Finnish Lapland there are areas where $\sigma_{\mathrm{SP}}$ is somewhat higher: in Eastern Lapland at a site that is close to the Kola Peninsula industrial emissions the 1-year (1994-1995) average $\sigma_{\mathrm{SP}} 550 \mathrm{~nm}$ ) was $16 \mathrm{Mm}^{-1}$ (Virkkula et al., 1997), close to that from the present study.
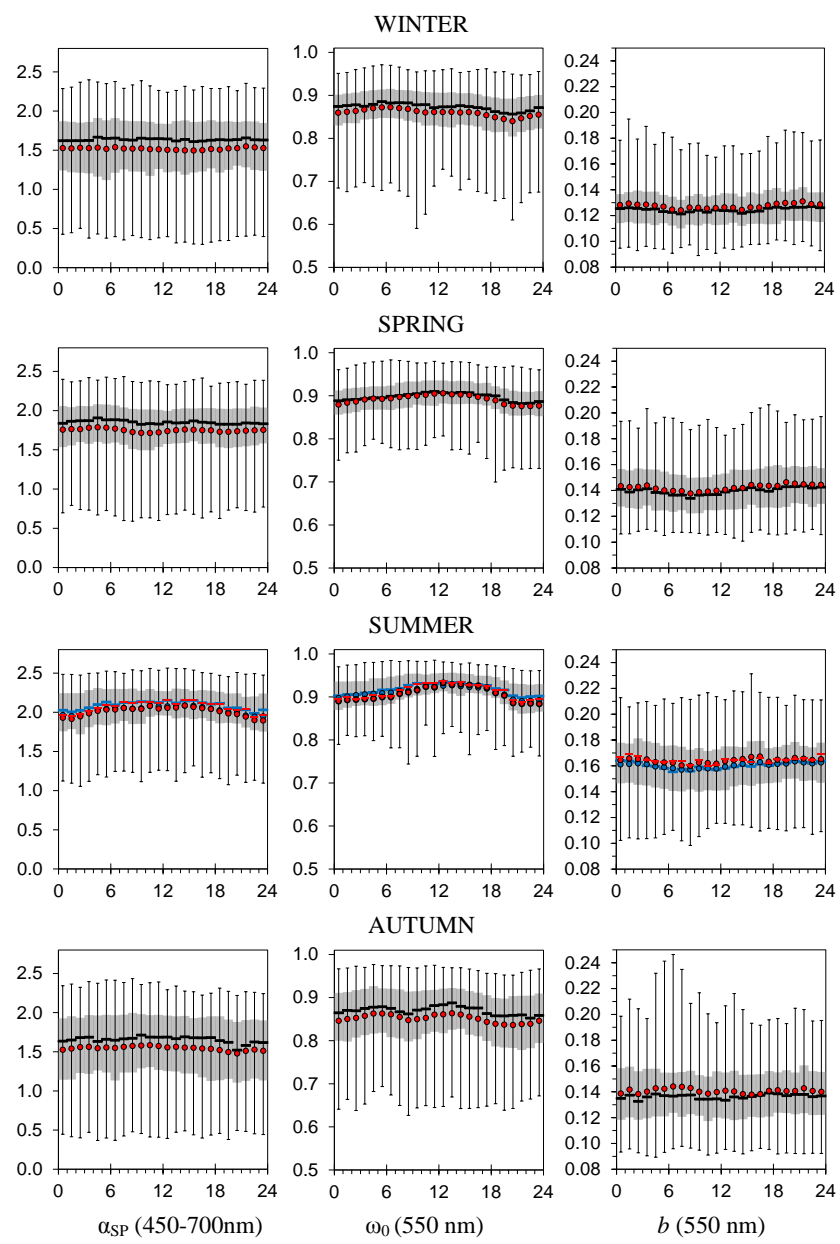

Fig. 7. Diurnal cycle of Ångström exponent of scattering $\left(\alpha_{\mathrm{SP}}\right)$, single-scattering albedo $\left(\omega_{0}\right)$ and backscatter fraction $(b)$ in four seasons in 13 October 2006-31 May 2009. Red dot: average; black line: median; grey bar: 25 th to 75 th percentiles; thin error bar: 2.5 th to 97.5 th percentiles. For the summer data the red symbols represent the mean and median of those data where $\mathrm{RH}_{\mathrm{NEPH}}<50 \%$ and the respective blue symbols all data without $\mathrm{RH}$ filtering.

The average aerosol forcing efficiency $\Delta F / \delta=$ $-23 \pm 5 \mathrm{~W} \mathrm{~m}^{-2}$ is comparable to those reported by Delene and Ogren (2002) from four stations in North America, with station averages ranging from $-23.5 \mathrm{~W} \mathrm{~m}^{-2}$ in the most polluted continental site to $-25.6 \mathrm{~W} \mathrm{~m}^{-2}$ at an anthropogenically influenced marine station. These numbers should be compared with caution, however, especially because $\sigma_{\mathrm{AP}}$ was measured with different methods.

\subsection{Seasonal and diurnal cycles}

The seasonal cycles were analyzed from hourly-averaged data classified according to the measurement month (Fig. 5) and according to the hour of the day in four seasons: winter (December-February), spring (March-May), summer 
(June-August), and autumn (September-November) (Figs. 6 and 7, Table 2). So the latter two figures show diurnal cycles in different seasons.

Figure 5 shows the averages, medians and 95 and 50 percent ranges of the data and also of the relative humidity measured by the nephelometer. There it is obvious that in July and August the WMO/GAW-recommended RH upper limit of $50 \%$ was frequently exceeded. The descriptive statistics of the optical properties were calculated twice: by keeping all data and by excluding those data where $\mathrm{RH}_{\mathrm{NEPH}}$ exceeded $50 \%$ (Fig. 5). It is obvious from Fig. 5 that in summer the mean scattering and absorption coefficients are lower when the data with high humidity are excluded. The largest difference is in the August data, for $\sigma_{\mathrm{SP}}$ the mean was 17.5 $\mathrm{Mm}^{-1}$ and $9.2 \mathrm{Mm}^{-1}$ by using all data and by excluding the higher humidity data. For $\sigma_{\mathrm{AP}}$ the respective values were 1.62 and $0.89 \mathrm{Mm}^{-1}$. Such large differences are not due to hygroscopic growth but due to excluding about $57 \%$ of data in August. Within these excluded data there were periods when both the measured $\sigma_{\mathrm{SP}}$ and that modeled from dry size distributions exceeded several tens of $\mathrm{Mm}^{-1}$, as will be discussed below when comparing the measured and modeled scattering. Based on this argument all data were taken into account in the following discussion on the seasonal variation.

Even though the highest hourly scattering coefficients were observed in winter and spring the seasonal cycle of monthly averages or medians is not strong. The maximum monthly averages $\left(\sigma_{\mathrm{SP}}>20 \mathrm{Mm}^{-1}\right)$ were observed in winter and spring but there were also some summer and autumn months with monthly averages close to $20 \mathrm{Mm}^{-1}$. The highest average $\sigma_{\mathrm{SP}}\left(22.4 \mathrm{Mm}^{-1}\right)$ was in March and the lowest in November $\left(12.2 \mathrm{Mm}^{-1}\right)$ and almost as low in June $\left(12.9 \mathrm{Mm}^{-1}\right)$ so the ratio of the highest to the lowest average was $\sim 1.8$. If each month of the whole 32 -month period is taken separately, the ratio of the highest $\left(28.2 \mathrm{Mm}^{-1}\right)$ to the lowest average $\left(8.2 \mathrm{Mm}^{-1}\right)$ was somewhat higher, 3.4. But in what ever way it is calculated, the seasonal cycle of $\sigma_{\mathrm{SP}}$ at SMEAR II is weaker than at the Pallas GAW station in Finnish Lapland where the maximum monthly averages were observed in May-July and they were about 4-5 higher than the minima, observed in autumn (Aaltonen et al., 2006).

The seasonal cycle of absorption is stronger than that of scattering. The highest average $\sigma_{\mathrm{AP}}$ in Fig. 5 was in February $\left(3.1 \mathrm{Mm}^{-1}\right)$ and the lowest in July $\left(1.1 \mathrm{Mm}^{-1}\right)$ so the ratio of the highest to the lowest average was $\sim 2.8$. And again, if each month of the whole 32-month period is taken separately, the ratio of the highest $\left(4.4 \mathrm{Mm}^{-1}\right)$ to the lowest average $\left(0.86 \mathrm{Mm}^{-1}\right)$ was somewhat higher, 5.1 .

The intensive optical properties all have clear seasonal cycles as was already mentioned above. In winter months the aerosol is darkest, with monthly means of $\omega_{0}<0.9$ and lighter in summer, with monthly means of $\omega_{0}>0.9$. The lowest monthly median $\alpha_{\mathrm{AP}}$ values, $\sim 1.2$, were observed in summer, and the largest values, $\sim 1.4$ in winter (Fig. 5, Table 2). These values suggest that the light absorbing particles observed in summer time are closer to pure LAC than in winter and that the sources of absorbing aerosol are different in winter and summer.

The highest $\alpha_{\mathrm{SP}}$ values were observed in spring and summer indicating the dominance of small particles, smallest in autumn and winter (Fig. 5, Table 2), suggesting the dominance of large particles, if $\alpha_{\mathrm{SP}}$ is interpreted as discussed above. The relationship of $\alpha_{\mathrm{SP}}$ with actual size distributions will be discussed below. The backscatter fraction also has a clear seasonal cycle with higher values in summer which also suggests smaller dominant particle sizes in summer. Because both $\omega_{0}$ and $b$ have their maxima in summer the aerosol forcing efficiency reaches minimum, average and median $\Delta F / \delta$ were $-27.3 \pm 3.1$ and $-27.5 \mathrm{~W} \mathrm{~m}^{-2}$ (Table 2). These values were calculated with all the data but even if only those data are taken into account when $\mathrm{RH}_{\mathrm{NEPH}}<50 \%$ the respective values are practically the same: $-27.4 \pm 3.2$ and $-27.8 \mathrm{~W} \mathrm{~m}^{-2}$. The main point is that these values are lower than those in other seasons. This means that the aerosols observed in summer have the potential to cool the atmosphere more efficiently than those observed in winter. In the calculation of $\Delta F / \delta$ the surface reflectance $R_{\mathrm{S}}=0.15$. If $\Delta F / \delta$ is recalculated with $R_{\mathrm{S}}>0.6$, more appropriate to that of a snow-covered ground, it becomes positive. This means that the aerosol observed in winter heats the atmosphere.

Another important factor that definitely affects the radiative forcing by aerosols is their hygroscopic growth. When they grow due to increasing $\mathrm{RH}$ their $\omega_{0}$ increases which leads to lower $\Delta F / \delta$. The growth of particles also affects $\Delta F / \delta$ in the other direction: the backscatter fraction $b$ and so also he upscatter fraction $\beta$ decrease with increasing particle size. In addition it should be taken into account that the uptake of water changes the refractive index of the particles. A quantitative analysis of these effects and further sensitivity analyses are omitted in this work.

The diurnal cycles were calculated for $\sigma_{\mathrm{SP}}, \sigma_{\mathrm{AP}}, \mathrm{RH}_{\mathrm{NEPH}}$, $\alpha_{\mathrm{SP}}, \omega_{0}$, and $b$ in four seasons in 13 October 200631 May 2009 (Figs. 6 and 7). For the summer data the statistics were calculated twice: including and excluding those data when $\mathrm{RH}_{\mathrm{NEPH}}<50 \%$. For other seasons this filtering resulted in figures that were so similar to the unfiltered ones that a difference could not be seen by naked eye. Therefore only the unfiltered statistics are shown in these figures. For $\sigma_{\mathrm{SP}}$ a diurnal weak in all seasons observable even though in spring and summer there is some cycling: the highest mean and median values were observed in the morning and lowest in the evening. It may be argued that the diurnal cycle of $\sigma_{\mathrm{SP}}$ in summer is due to the diurnal cycle of mean and median $\mathrm{RH}_{\mathrm{NEPH}}$ that also have maxima in the morning. But $\mathrm{RH}_{\mathrm{NEPH}}$ also has maxima in the evening but $\sigma_{\mathrm{SP}}$ does not so this is not a likely explanation. A comparison with the diurnal cycle of $\sigma_{\mathrm{SP}}$ in spring supports this because the mean and median cycles are very similar to those in summer even though $\mathrm{RH}_{\mathrm{NEPH}}$ has no observable cycle in spring. The low median values of the RH-filtered $\sigma_{\mathrm{SP}}$ in summer at 06:00 to 09:00 is 
Table 2. Statistical summary of hourly-averaged aerosol optics data in winter (December-February), spring (March-May), summer (June-August), and autumn (September-November). Units as in Table 1.

\begin{tabular}{l|rr|rr|rr|rr}
\hline & \multicolumn{2}{|c|}{ Winter } & \multicolumn{2}{c|}{ Spring } & \multicolumn{2}{c|}{ Summer } & \multicolumn{2}{c}{ Autumn } \\
\cline { 2 - 8 } & AVE \pm STD & MED & AVE \pm STD & MED & AVE \pm STD & MED & AVE \pm STD & MED \\
\hline$\sigma_{\mathrm{SP}}(450 \mathrm{~nm})$ & $27 \pm 29$ & 16 & $28 \pm 33$ & 17 & $25 \pm 19$ & 21 & $21 \pm 23$ \\
$\sigma_{\mathrm{SP}}(550 \mathrm{~nm})$ & $20 \pm 22$ & 12 & $20 \pm 23$ & 12 & $17 \pm 13$ & 14 & $15 \pm 17$ & 13 \\
$\sigma_{\mathrm{SP}}(700 \mathrm{~nm})$ & $13 \pm 14$ & 8 & $13 \pm 14$ & 8 & $10 \pm 7$ & 8 & $10 \pm 11$ & 7 \\
$b(450 \mathrm{~nm})$ & $0.11 \pm 0.02$ & 0.11 & $0.13 \pm 0.02$ & 0.12 & $0.14 \pm 0.03$ & 0.14 & $0.13 \pm 0.04$ & 0.12 \\
$b(550 \mathrm{~nm})$ & $0.13 \pm 0.02$ & 0.12 & $0.14 \pm 0.02$ & 0.14 & $0.16 \pm 0.03$ & 0.16 & $0.14 \pm 0.03$ & 0.14 \\
$b(700 \mathrm{~nm})$ & $0.17 \pm 0.03$ & 0.16 & $0.19 \pm 0.05$ & 0.19 & $0.21 \pm 0.03$ & 0.21 & $0.18 \pm 0.05$ & 0.18 \\
$\sigma_{\mathrm{AP}}(450 \mathrm{~nm})$ & $3.8 \pm 3.5$ & 2.7 & $3.3 \pm 4.3$ & 2.0 & $1.9 \pm 1.5$ & 1.5 & $3.0 \pm 2.8$ & 2.1 \\
$\sigma_{\mathrm{AP}}(550 \mathrm{~nm})$ & $2.7 \pm 2.5$ & 1.9 & $2.3 \pm 3.0$ & 1.4 & $1.4 \pm 1.2$ & 1.1 & $2.1 \pm 2.0$ & 1.5 \\
$\sigma_{\mathrm{AP}}(700 \mathrm{~nm})$ & $2.0 \pm 1.8$ & 1.4 & $1.8 \pm 2.3$ & 1.1 & $1.1 \pm 0.9$ & 0.9 & $1.6 \pm 1.5$ & 1.1 \\
$\alpha_{\mathrm{SP}}$ & $1.52 \pm 0.51$ & 1.63 & $1.75 \pm 0.44$ & 1.85 & $2.03 \pm 0.35$ & 2.09 & $1.55 \pm 0.53$ & 1.66 \\
$\alpha_{\mathrm{AP}}$ & $1.42 \pm 0.17$ & 1.41 & $1.37 \pm 0.17$ & 1.37 & $1.20 \pm 0.20$ & 1.20 & $1.38 \pm 0.23$ & 1.35 \\
$\omega_{0}(550 \mathrm{~nm})$ & $0.86 \pm 0.07$ & 0.87 & $0.89 \pm 0.05$ & 0.90 & $0.91 \pm 0.05$ & 0.92 & $0.85 \pm 0.09$ & 0.87 \\
$m_{\mathrm{r}}$ & $1.514 \pm 0.055$ & 1.516 & $1.516 \pm 0.063$ & 1.509 & $1.527 \pm 0.043$ & 1.527 & $1.512 \pm 0.061$ & 1.511 \\
$m_{\mathrm{i}}$ & $0.025 \pm 0.016$ & 0.021 & $0.016 \pm 0.011$ & 0.015 & $0.012 \pm 0.008$ & 0.010 & $0.024 \pm 0.018$ & 0.019 \\
$\Delta F / \delta$ & $-19.9 \pm 4.0$ & -20.5 & $-24.5 \pm 3.4$ & -24.8 & $-27.3 \pm 3.1$ & -27.5 & $-20.5 \pm 5.2$ & -21.5 \\
\hline
\end{tabular}

due to small amount of data points. For $\sigma_{\mathrm{AP}}$ the diurnal cycle is much clearer, especially in summer, with or without the RH filtering (Fig. 6). Minimum average and median $\sigma_{\mathrm{AP}}$ is observed at about noon or afternoon. This may be explained with the well-known phenomenon: in summer there is also a strong diurnal cycle of mixing layer height. It is lowest at night and highest in the afternoon which leads to dilution of pollutants, such as LAC in the boundary layer. Why then is the diurnal cycle of $\sigma_{\mathrm{SP}}$ clearly weaker? A possible explanation is that during the day organics that are formed in the forest condense on the existing LAC particles. It leads to an increase of $\omega_{0}$ towards noon and afternoon especially in spring and summer (Fig. 7). Here the RH filtering has a negligible effect. The diurnal cycle of $\alpha_{\mathrm{SP}}$ is clearest in summer and qualitatively similar to that of $\omega_{0}$, maximum is reached in the afternoon. The backscatter fraction diurnal cycle is weakest of the intensive parameters but there is some observable cyclic variation in the median and average values in spring and summer. Contrary to $\alpha_{\mathrm{SP}}$ and $\omega_{0}$, the minimum of mean and median $b$ is now in the morning from where it grows slowly towards midnight which suggests there is a slow decrease in the dominant particle size. A good explanation could not be given.

\subsection{Scattering coefficient and selected extensive aerosol properties}

\subsubsection{Mass vs. $\sigma_{\mathrm{SP}}$}

It has been well known for decades that aerosol mass concentration and scattering coefficient are highly correlated (e.g., Charlson et al., 1967) and it is so at SMEAR II as well.
The time series of aerosol volume concentration $(V)$ and $\sigma_{\mathrm{SP}}$ tracked well each other (Fig. 2) which results in a good correlation in the scatter plot of $\sigma_{\mathrm{SP}}$ vs. mass concentration (Fig. 8). The mass concentration was calculated assuming the density of $1.5 \mathrm{~g} \mathrm{~cm}^{-3}$ as explained in Sect. 2.5. Linear fits yield $\mathrm{PM}_{10}$ mass scattering efficiencies $4.4 \pm 1.2 \mathrm{~m}^{2} \mathrm{~g}^{-1}$, $3.1 \pm 0.9 \mathrm{~m}^{2} \mathrm{~g}^{-1}$, and $2.0 \pm 0.9 \mathrm{~m}^{2} \mathrm{~g}^{-1}$, for $\lambda=450 \mathrm{~nm}$, $550 \mathrm{~nm}$ and $700 \mathrm{~nm}$, respectively. The uncertainties above are the standard deviations of the slopes obtained from a linear fit. Actually the code that was used for calculating the regressions returns the standard error of the slope. The above standard deviations were calculated from std $=\sqrt{n} \cdot s e$, where $n$ is the number of observations $(=21904)$. The values above were calculated from a linear regression but they can also be calculated from the $\sigma_{\mathrm{SP}}-$ to- $-\mathrm{PM}_{10}$ ratio at each hour. The average ( \pm standard deviation) mass scattering efficiencies then become $3.7 \pm 1.2 \mathrm{~m}^{2} \mathrm{~g}^{-1}, 2.6 \pm 0.8 \mathrm{~m}^{2} \mathrm{~g}^{-1}$, and $1.7 \pm 0.6 \mathrm{~m}^{2} \mathrm{~g}^{-1}$, for $\lambda=450 \mathrm{~nm}, 550 \mathrm{~nm}$ and $700 \mathrm{~nm}$, respectively. Which ever way they are calculated, the results are in line with other published mass scattering efficiencies, for instance Hobbs et al. (1997), Malm and Hand (2007). Another point that can be seen in Fig. 8 is that a linear relationship between $\mathrm{PM}_{10}$ and $\sigma_{\mathrm{SP}}$ is not very good for the whole range of observations, especially at the lower range of concentrations. The power function $\sigma_{\mathrm{SP}}=2.12 \cdot m\left(\mathrm{PM}_{10}\right)^{1.12}$ obviously represents the relationship much better but then no mass scattering efficiency can be given. 


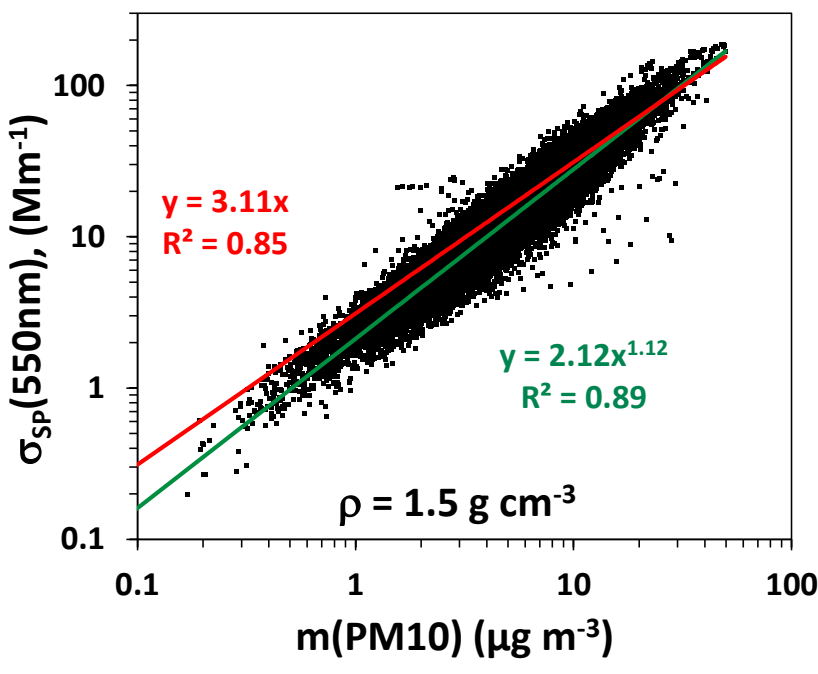

Fig. 8. Relationship of light scattering coefficient at $\lambda=550 \mathrm{~nm}$ and aerosol mass concentration $\left(D_{\mathrm{p}}<10 \mu \mathrm{m}\right)$ during the whole measurement period.

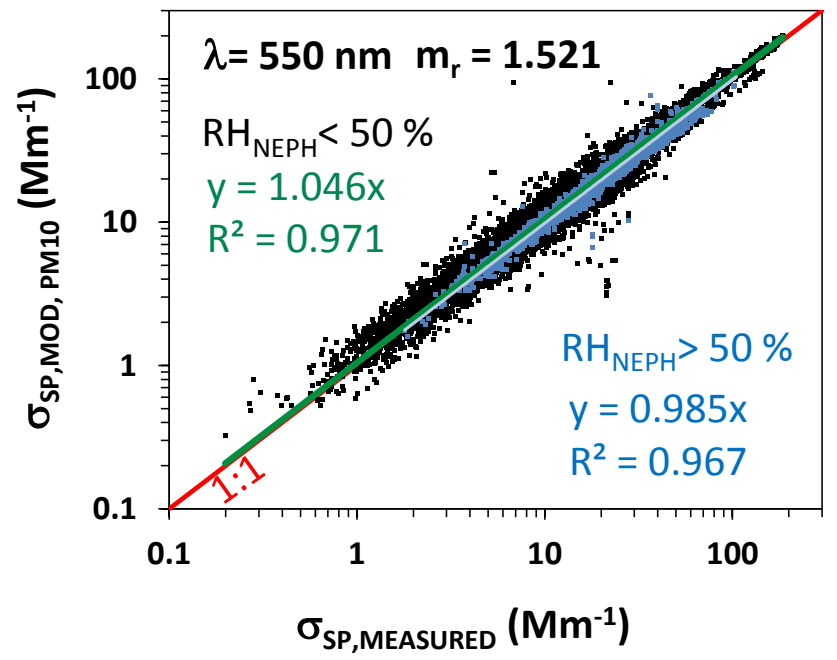

Fig. 9. Measured and modelled $\left(D_{\mathrm{p}}<10 \mu \mathrm{m}\right) \sigma_{\mathrm{SP}}$ at $550 \mathrm{~nm}$ by assuming purely scattering aerosol and using the refractive index of ammonium sulfate $(m=1.521+0 i)$ for the whole measurement period and for all particle sizes.

\subsubsection{Measured and modelled $\sigma_{\mathrm{SP}}$}

The calculation was done first by assuming that the aerosol is ammonium sulfate, and thus that the refractive index $m=m_{\mathrm{r}}=1.521$. The resulting scatter plot (Fig. 9) shows that this assumption is actually reasonably good. In the plot the data were again classified according to $\mathrm{RH}_{\mathrm{NEPH}}$ in two groups: those with $\mathrm{RH}_{\mathrm{NEPH}}<50 \%$ and those with $\mathrm{RH}_{\mathrm{NEPH}}>50 \%$. The data points measured at the higher $\mathrm{RH}_{\mathrm{NEPH}}$ were all inside the cluster of those measured at the lower $\mathrm{RH}_{\mathrm{NEPH}}$ so the effect does not seem to be very big. This is because even in the high-humidity data the $\mathrm{RH}_{\mathrm{NEPH}}$ was not very high: the average \pm standard deviation was $55 \pm 4 \%$. In the rest of the data $\mathrm{RH}_{\mathrm{NEPH}}$ was $30 \pm 9 \%$. When the slopes of the regression lines are compared, they are in the right order: in the low-humidity range the modelled $\sigma_{\mathrm{SP}}$ is larger than the measured one and in the high-humidity range the other way round. The regressions yield $\sigma_{\mathrm{SP}}($ modelled $)=1.046 \times \sigma_{\mathrm{SP}}($ measured $)$ for the low-humidity data points and $\sigma_{\mathrm{SP}}($ modelled $)=0.985 \times$ $\sigma_{\mathrm{SP}}$ (measured) for the high-humidity ones. This plot shows also a point that was referred to above when the seasonal cycles were calculated in Figs. 5-7: neglecting the data at $\mathrm{RH}_{\mathrm{NEPH}}>50 \%$ would result in too low averages and medians because in these data there were true high scattering coefficients that were calculated also from the dry size distributions.

There are also large deviations from the regression line even in the data with $\mathrm{RH}_{\mathrm{NEPH}}<50 \%$ : $10 \%$ of the $\sigma_{\mathrm{SP}}\left(\right.$ modelled)-to- $\sigma_{\mathrm{SP}}($ measured) ratios, calculated for each hour, were smaller than 0.9 and $10 \%$ of them, i.e., the 90th percentile are larger than 1.27. Part of these deviations may be explained by technical issues, such as noise in either the nephelometer or the size distribution measurements but largely by the assumption of a constant refractive index. The real aerosol was also absorbing with the absorption coefficient $\sigma_{\mathrm{AP}}$ varying approximately in the range $0.1-15 \mathrm{Mm}^{-1}$, which implies that the imaginary refractive index is not zero. Also the real refractive index varies because the chemical composition varies.

The iterative procedure discussed above was applied to all data. From the iterative process obtained average effective complex refractive index was $(1.517 \pm 0.057)+(0.019 \pm 0.015) i$ (Table 1$)$. The real part as actually very close to 1.521 , i.e., that of ammonium sulfate. However, there is a large range of refractive indices with $98 \%$ of them fitting between 1.363 and 1.659, probably reflecting variations in aerosol chemical composition. The highest imaginary refractive indices were obtained when aerosol was darkest but the relationship between $\omega_{0}$ and $m_{\mathrm{i}}$ is not linear. The seasonal averages and medians of the real refractive did not vary much but there was a seasonal cycle in the imaginary refractive index (Table 2). The highest $m_{\mathrm{i}}$ values were obtained for winter and lowest for summer, respectively and in between these values for spring and autumn, in agreement with the seasonal cycle of single-scattering albedo discussed above. A more detailed discussion of the effective refractive index will not be presented in the present paper.

Comparison of the measured and modelled $\sigma_{\mathrm{SP}}$ is the most important step in assessing the quality of scattering and size distribution measurements but going one step backwards is also informative. The integrand in Eq. (8) may actually be called the scattering size distribution

$$
\frac{d \sigma_{\mathrm{SP}}}{d \log D_{\mathrm{p}}}=Q_{\mathrm{SP}}\left(\lambda, D_{\mathrm{p}}, m\right) \frac{\pi D_{\mathrm{p}}^{2}}{4} \frac{d N}{d \log D_{\mathrm{p}}}
$$




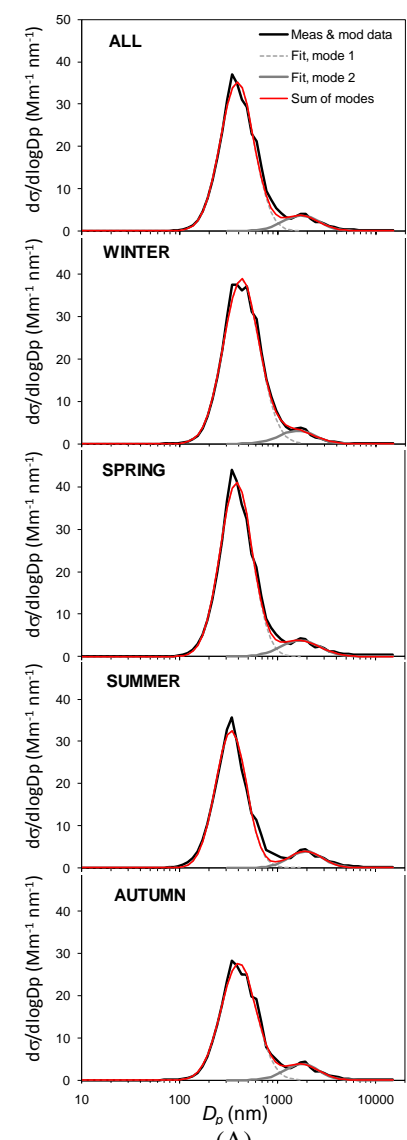

(A)

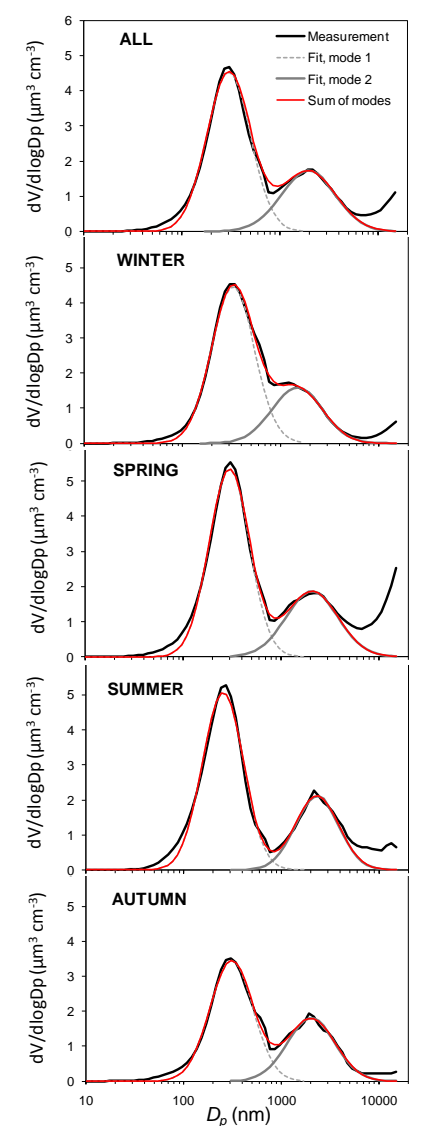

(B)

Fig. 10. Average size distribution of $\sigma_{\mathrm{SP}}$ and aerosol volume concentration and to the average size distributions fitted two lognormal modes and their sum in four seasons. Left: $d \sigma_{\mathrm{SP}} / d \log D_{\mathrm{p}}$; right $d V / d \log D_{\mathrm{p}}$.

The hourly scattering size distributions were averaged over the whole measurement period and over the four seasons: winter (December-February), spring (March-May), summer (June-August), and autumn (September-November). The average size distribution was clearly bimodal so two lognormal modes were fitted to the data, one submicron and one supermicron (Fig. 10). The fitting of two lognormal modes was done similarly for the volume size distributions $V\left(D_{\mathrm{p}}\right)$. The obtained modal parameters, the geometric mean diameter $\left(D_{\mathrm{g}}\right)$, the geometric standard deviations $\left(\sigma_{\mathrm{g}}\right)$ and the mode scattering coefficients and volume concentrations are given in Table 3. Above scattering was calculated with the constant real refractive index $m_{\mathrm{r}}=1.521$ only, the effect of varying the imaginary refractive index on the modal structure of the scattering size distribution is negligible.

Integration of the $\sigma_{\mathrm{SP}}$ size distributions and division by the total $\sigma_{\mathrm{SP}}$ yields the cumulative and normalized $\sigma_{\mathrm{SP}}$ size distributions that were calculated for the whole data and the four seasons (Fig. 11). The average contribution of submicron particles to total scattering was $92 \%, 90 \%, 88 \%$, and

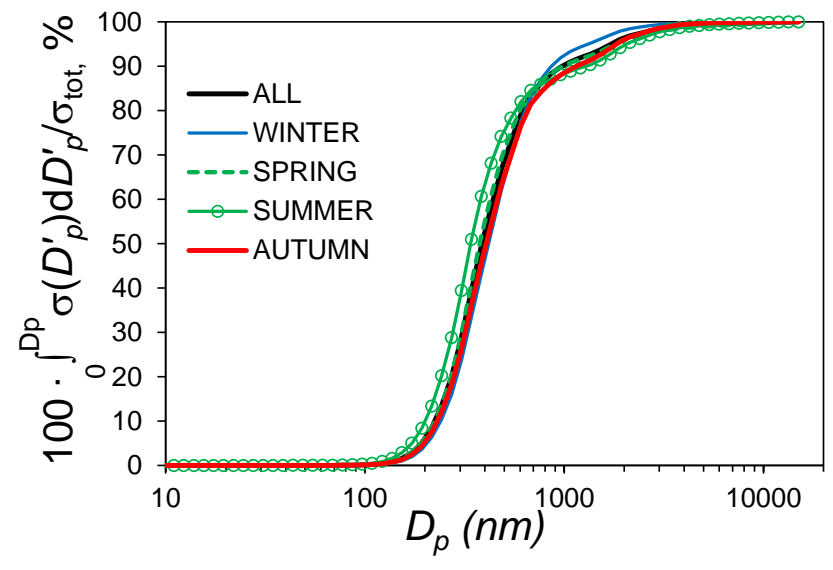

Fig. 11. Cumulative and normalized modelled $\sigma_{\mathrm{SP}}$ at $\lambda=550 \mathrm{~nm}$ in all data and in four seasons.

$88 \%$ in winter, spring, summer, and autumn, respectively, and $90 \%$ on the average of all data. Of course it has to be kept in mind that these estimates are based on using constant refractive index for the whole size distribution and for all time steps. The average contribution of particles smaller than $100 \mathrm{~nm}$ to total scattering $(=R 0.1)$ was $0.2 \%$ but this number varied so that in the pollution episodes with $\sigma_{\mathrm{SP}}>100 \mathrm{Mm}^{-1}$ it was only about $0.02 \pm 0.01 \%$ and at the end of some new particle formation events it was as high as $1-2 \%$. The 98th percentile of the cumulative distribution of $R 0.1$ was $0.96 \%$.

\subsubsection{Condensation sink vs. $\sigma_{\mathrm{SP}}$}

The condensation sink (CS) is a measure of how rapidly condensable vapor molecules will condense on the existing aerosol and it is directly (but not linearly) proportional to aerosol surface area concentration and inversely proportional to the strength of new particle formation so that low values favor new particle formation (e.g., Pirjola et al., 1999; Dal Maso et al., 2002; Kulmala et al., 2005). Light scattering on the other hand is also directly, but not linerly proportional to surface area. Even though the scattering efficiency $Q_{\text {SP }}$ does not increase monotonically, it is easy to show, even though omitted here that for realistic particle size distributions the integral of the product of $Q_{\mathrm{SP}}$ and the surface area concentration $\pi D_{\mathrm{p}}^{2} n\left(D_{\mathrm{p}}\right)$, which is in the integrand of Eq. (8), increases monotonically with increasing surface area concentration. So, CS and $\sigma_{\mathrm{SP}}$ should in principle be positively correlated and low $\sigma_{\mathrm{SP}}$ should favor new particle formation. The CS and $\sigma_{\mathrm{SP}}$ were compared here to get information on whether $\sigma_{\mathrm{SP}}$ could be used as a proxy for CS when estimating the potential for new particle formation at sites where no size distribution data are available. The CS was calculated from the size distributions as presented by Dal Maso et al. (2002) and for dry aerosols only. There is indeed a clear positive correlation between the measured $\sigma_{\mathrm{SP}}$ and CS calculated from the size distributions (Fig. 12). 
Table 3. The modal parameters of the major modes of scattering $(\lambda=550 \mathrm{~nm})$ and volume size distributions obtained from fitting lognormal modes to the average size distribution of all data, and the averages of the four seasons. $D_{\mathrm{g}}$ is the geometric mean and $\sigma_{\mathrm{g}}$ the geometric standard deviation of the mode, $\sigma_{\mathrm{SP}}$ is the integrated scattering of the mode and $V$ is the integrated volume of the mode.

\begin{tabular}{lrrc|rrc}
\hline & \multicolumn{5}{c}{ Submicron mode } & \multicolumn{3}{c}{ Supermicron mode } \\
\cline { 2 - 7 } & \multicolumn{6}{c}{ Scattering size distribution } \\
\hline \multirow{2}{*}{$D_{\mathrm{g}}(\mathrm{nm})$} & $\sigma_{\mathrm{g}}$ & $\sigma_{\mathrm{SP}}\left(\mathrm{Mm}^{-1}\right)$ & $D_{\mathrm{g}}(\mathrm{nm})$ & $\sigma_{\mathrm{g}}$ & $\sigma_{\mathrm{SP}}\left(\mathrm{Mm}^{-1}\right)$ \\
\hline Winter & 383 & 1.49 & 15.3 & 1704 & 1.52 & 1.68 \\
Spring & 423 & 1.53 & 18.0 & 1568 & 1.52 & 1.41 \\
Summer & 377 & 1.47 & 17.2 & 1689 & 1.60 & 1.91 \\
Autumn & 334 & 1.44 & 12.9 & 1918 & 1.49 & 1.70 \\
& 399 & 1.52 & 12.6 & 1752 & 1.48 & 1.64 \\
\hline & & \multicolumn{7}{c}{ Volume size distribution } & & \\
\hline All & 300 & 1.67 & 2.53 & 1951 & 1.89 & 1.20 \\
Winter & 326 & 1.66 & 2.45 & 1474 & 1.81 & 1.02 \\
Spring & 295 & 1.61 & 2.77 & 2073 & 1.85 & 1.25 \\
Summer & 252 & 1.62 & 2.67 & 2315 & 1.67 & 1.18 \\
Autumn & 308 & 1.67 & 1.92 & 2024 & 1.76 & 1.11 \\
\hline
\end{tabular}

\section{4 Ångström exponent of scattering and particle size}

The Ångström exponent of extinction (Ångström, 1929) is used often as a qualitative indicator of the dominant particle size, with large values $(>2)$ indicating the dominance of small particles, and small values $(<1)$ the dominance of large particles. The usage of the Ångström exponent this way is common in operational sunphotometry (e.g., Holben et al., 2001; Gobbi et al., 2007) and satellite retrieval of aerosol optical properties (e.g., Higurashi and Nakajima, 1999; King et al., 1999; Liu et al., 2008) even though it is well known that this is just a crude approximation. For monomodal size distributions the relationship holds up to approximately $D_{\mathrm{p}}=1 \mu \mathrm{m}$ at the visible wavelengths but for multimodal size distributions the relationship is more complicated: Schuster et al. (2006) studied both unimodal and bimodal size distributions and found that for bimodal size distributions the relationship may in some cases become opposite. Garland et al. (2008) compared $\alpha_{\text {SP }}$ with the effective mode diameter of lognormal fits to submicron aerosol size distribution.

Here the relationship between particle size distributions and $\alpha_{\text {SP }}$ is studied by comparing the latter with the following weighted mean diameters: the count mean diameter

$\mathrm{CMD}=\frac{\sum D_{\mathrm{p}, i} N_{i}}{N_{\mathrm{tot}}}$

the surface mean diameter

$\mathrm{SMD}=\frac{\sum D_{\mathrm{p}, i} S_{i}}{S_{\mathrm{tot}}}=\frac{\sum D_{\mathrm{p}, i}^{3} N_{i}}{\sum D_{\mathrm{p}, i}^{2} N_{i}}$

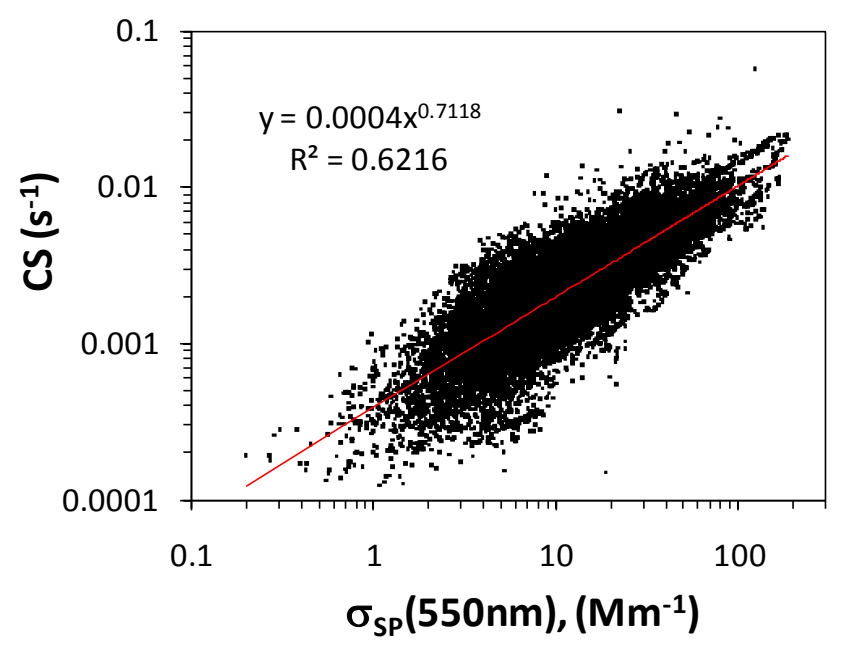

Fig. 12. Relationship of condensation sink (CS) and $\sigma_{\mathrm{SP}}$ at $\lambda=$ $550 \mathrm{~nm}$.

the volume mean diameter

$\mathrm{VMD}=\frac{\sum D_{\mathrm{p}, i} V_{i}}{V}$

the scattering mean diameter

$\mathrm{ScMD}=\frac{\sum D_{\mathrm{p}, i} \sigma_{\mathrm{SP}, i}}{\sigma_{\mathrm{SP}}}$

and the condensation sink mean diameter

$\mathrm{CsMD}=\frac{\sum D_{\mathrm{p}, i} \mathrm{CS}_{i}}{\mathrm{CS}}$ 
In addition, size distributions were also simulated. Lognormal size distributions were generated with the geometric mean diameter $D_{\mathrm{g}}$ varying from $50 \mathrm{~nm}$ to $3.5 \mu \mathrm{m}$ and the geometric standard deviation $\sigma_{\mathrm{g}}=1.5$ and 2.0. These size distributions were used for calculating $\sigma_{\mathrm{SP}}$ at the nephelometer wavelengths $\lambda=450,550$, and $700 \mathrm{~nm}$ from Eq. (4) using the refractive index of ammonium sulfate and subsequently $\alpha_{\text {SP }}$ from Eq. (4). All the above weighted mean diameters were then calculated from these simulated data. Only unimodal size distributions were used. The purpose of these simulations is only to visualize the qualitative relationship of increasing particle mean diameter and decreasing $\alpha_{\mathrm{SP}}$ and show whether this is similar for real data. We will not repeat the analysis of Schuster et al. (2006) by using also simulated bimodal size distributions.

The relationship of the mean diameter and $\alpha_{\mathrm{SP}}$ in the simulation is just the typically assumed inverse relationship: the larger the $\alpha_{\text {SP }}$ the smaller the mean diameter of the particle population (Fig. 13). This applies to all weighted mean diameters of the simulated size distributions. In the real SMEAR II data it is somewhat different (Fig. 13). For the CMD the relationship is just the opposite: the larger $\alpha_{\mathrm{SP}}$ the larger is the CMD. This is due to the bimodality of the particle number size distributions. The CsMD did not have a clear dependency on $\alpha_{\mathrm{SP}}$ at all, also contrary to the values obtained from simulations with a single mode. For the other mean diameters ScMD, SMD, and VMD the relationships are closer to those from the simulations. Interestingly, the dependency of ScMD is very similar both calculated by fitting to the real data $(1328 \mathrm{~nm}) \cdot \exp \left(-0.44 \cdot \alpha_{\mathrm{SP}}\right)$ and to the simulated data. There the dependency was $(854 \mathrm{~nm}) \cdot \exp \left(-0.44 \cdot \alpha_{\mathrm{SP}}\right)$.

These relationships are qualitatively similar to those observed by Garland et al. (2008) from the data measured in Guangzhou, China at a considerably more polluted site. Garland et al. (2008) compared $\alpha_{\mathrm{SP}}$ with the effective mode diameters from monomodal lognormal fits to measured submicron size distributions, so the diameters they compared were not quite the same as in the present work. Still, they also observed that for the CMD the relationship is not inverse whereas for SMD and VMD it was, just like in the present work.

\subsection{Relationships of single-scattering albedo}

The single-scattering albedo $\omega_{0}$ at $\lambda=550 \mathrm{~nm}$ was compared with $\sigma_{\mathrm{SP}}, \sigma_{\mathrm{AP}}, \mathrm{CMD}$, and $\alpha_{\mathrm{AP}}$ (Fig. 14). The first two comparisons were done to find out what were the general pollution levels when the darkest and the lightest aerosol was observed. $\omega_{0}$ was compared with $\alpha_{\mathrm{AP}}$ since the wavelength dependency of absorption is related to the absorbing material. $\omega_{0}$ was also compared with CMD to see whether the data available would yield any information on the size of the absorbing aerosol. For the comparisons all data were classified according to $\sigma_{\mathrm{SP}}$ into bins $\sigma_{\mathrm{SP}}<3.2,3.2-10,10-31.6$, $31.6-100$, and $\sigma_{\mathrm{SP}}>100 \mathrm{Mm}^{-1}$, and according to $\omega_{0}$ into
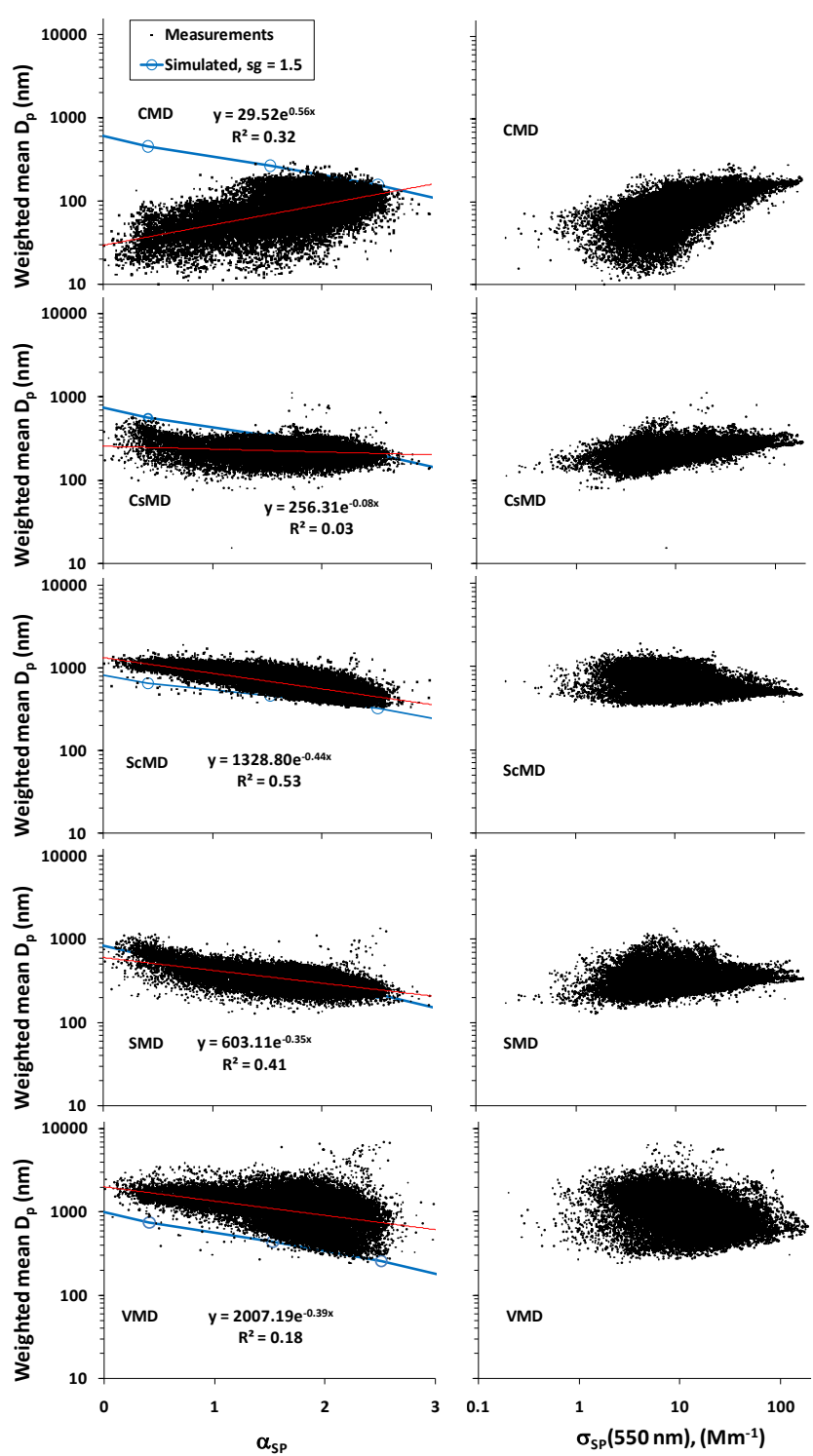

Fig. 13. Weighted mean diameters $\left(D_{\mathrm{p}}<10 \mu \mathrm{m}\right)$ as a function of $\alpha_{\mathrm{SP}}$ and $\sigma_{\mathrm{SP}}$. The red lines are exponential curves $D_{p 0} \exp (-k$. $\alpha_{\mathrm{SP}}$ ) fitted to the data and the blue lines respective weighted mean diameters calculated from simulated lognormal size distributions, see text for details.

bins $\omega_{0}<0.5,0.5-0.6,0.6-0.7,0.7-0.8,0.8-0.85,0.85-$ $0.90,0.90-0.95,0.95-1.0$. Selected descriptive statistical values of the data were calculated for each bin. In addition, the fraction of data in each of the bins were calculated (Fig. 14e-f).

The mean and median $\omega_{0}$ increased with increasing scattering. The darkest aerosol, i.e., the lowest $\omega_{0}$ was observed in the lowest $\sigma_{\mathrm{SP}}$ range $\left(<3 \mathrm{Mm}^{-1}\right)$ which comprises $4.6 \%$ of the data: the median $\omega_{0}$ was 0.825 but there was also the largest $95 \% \omega_{0}$ range, from 0.54 to 0.96 (Fig. 14a and e). The range decreased with increasing $\sigma_{\mathrm{SP}}$ so that in the 


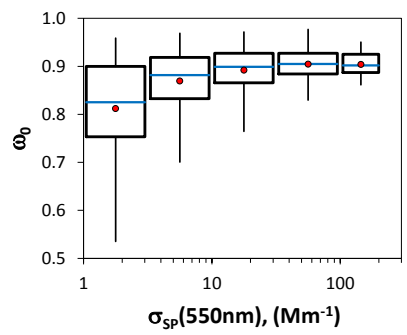

(A)

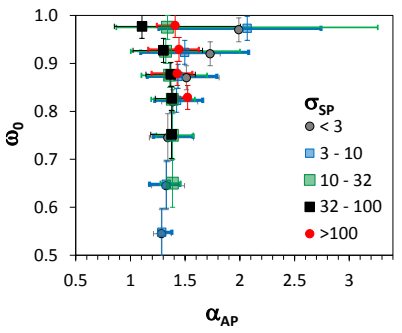

(C)

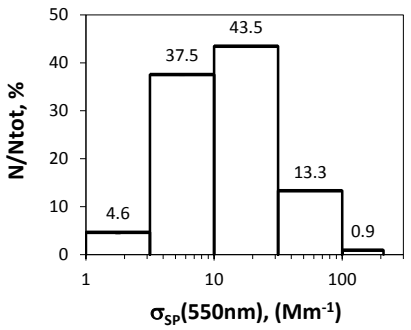

(E)

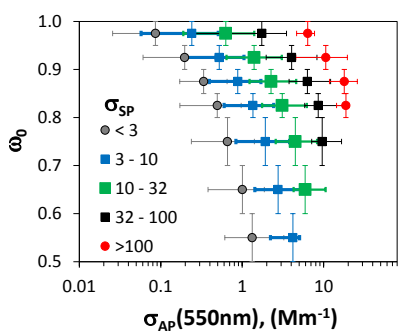

(B)

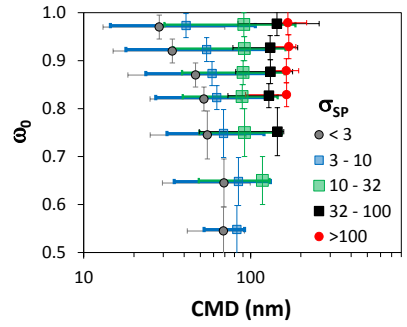

(D)

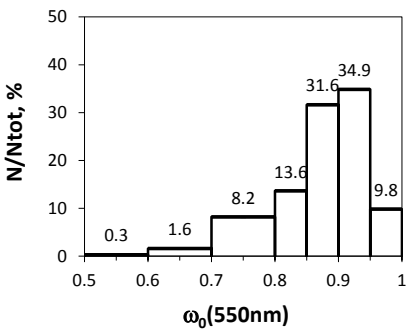

(F)
Fig. 14. Single-scattering albedo $\left(\omega_{0}\right)$ at $\lambda=550 \mathrm{~nm}$ as a function of (A) scattering coefficient $\left(\sigma_{\mathrm{SP}}\right),(\mathbf{B})$ absorption coefficient $\left(\sigma_{\mathrm{AP}}\right)$ and $\sigma_{\mathrm{SP}},(\mathbf{C})$ Ångström exponent of absorption $\left(\alpha_{\mathrm{AP}}\right)$ and $\sigma_{\mathrm{SP}}$, and (D) particle size (count mean diameter); (E) the fraction of data in the $\sigma_{\mathrm{SP}}$ bins and $(\mathbf{F})$ the fraction of data in the $\omega_{0}$ bins. In $\mathrm{A}$ the red circle is the average, the blue horizontal line the median, the box the 25th to 75th percentile range and the vertical error bar the 2.5 th to 97.5 th percentile range of $\omega_{0}$ in each of the five $\sigma_{\mathrm{SP}}$ bins. In (B), (C), and (D) the symbols are color-coded into the five $\sigma_{\mathrm{SP}}$ bins, the vertical error bars represent the seven $\omega_{0}$ bins, the symbol is the median and the horizontal error bars the $95 \%$ range of the respective data.

strongest long-range transported pollution episodes $\left(\sigma_{\mathrm{SP}}>\right.$ $100 \mathrm{Mm}^{-1}, \sim 1 \%$ of data) the median $\omega_{0}$ was 0.90 and $95 \%$ range was 0.86 to 0.95 . Light aerosol with $\omega_{0}>0.95$ was observed in all $\sigma_{\mathrm{SP}}$ bins but the darkest aerosol, $\omega_{0}<0.6$, $0.3 \%$ of data, only in the lowermost $\sigma_{\mathrm{SP}}$ bins (Fig. 14b and f). The low $\omega_{0}$ values suggest that in these cases aerosol is essentially pure LAC which is supported by the narrow range of $\alpha_{\mathrm{AP}}$ (Fig. 14c).

At high values of $\omega_{0}(>0.95), 9.8 \%$ of data, the Ångstöm exponent of absorption $\alpha_{\mathrm{AP}}$ varied in a large range from 0.9 to $>3$. The high $\alpha_{\mathrm{AP}}$ may be associated with particles in different types of biomass burning smoke, as found, e.g., by Lewis et al. (2008). Schnaiter et al. (2005) determined
$\alpha_{\mathrm{AP}}=1.3 \pm 0.1$ for particles in diesel exhaust and a range 1.5 to 1.9 for particles in biomass burning smoke. For the darker aerosol, i.e., when $\omega_{0}<0.8,10.1 \%$ of observations, the average ( \pm standard deviation) $\alpha_{\mathrm{AP}}$ was $1.38 \pm 0.12$. At $\sigma_{\mathrm{SP}}>$ $100 \mathrm{Mm}^{-1}$ the average $\alpha_{\mathrm{AP}}$ was very similar, $1.43 \pm 0.11$ even at high values of $\omega_{0}$. Typically $\omega_{0}$ for wood-burning smoke is $>0.7$ whereas for fresh diesel exhaust particles it is in the range of $<0.6$ (e.g., Bergstrom et al., 2007 and references therein).

The effective size of the particles, expressed here as the count mean diameter (CMD), varied from some tens of $\mathrm{nm}$ to $\sim 200 \mathrm{~nm}$ (Fig. 14d). The smallest average CMD, $33 \pm 15 \mathrm{~nm}$ was calculated in the bin $\omega_{0}>0.95$ and $\sigma_{\mathrm{SP}}<3.2 \mathrm{Mm}^{-1}$, the 2.5 th percentile was $13 \mathrm{~nm}$. These CMDs are typical in new particle formation episodes. The largest CMDs were in the clear long-range transported pollution episodes: for $\sigma_{\mathrm{SP}}>100 \mathrm{Mm}^{-1}$ the mean CMD was $165 \pm 20 \mathrm{~nm}$. In the darkest $\omega_{0}$ bin $95 \%$ of CMDs varied between 43 and $92 \mathrm{~nm}$, the mean was $70 \pm 17 \mathrm{~nm}$. Fresh combustion exhaust aerosol, either from diesel engines or biomass burning is often in this size range. Most of the particle number emitted by engines is in the range $<50 \mathrm{~nm}$ (e.g., Kittelson, 1998) but roadside measurements have shown that LAC mode mean diameter varied from about 50 to $70 \mathrm{~nm}$ (Casati et al., 2007). It is possible that the darkest aerosols were from some diesel vehicle exhaust: the size, $\omega_{0}$, and the associated $\alpha_{\mathrm{AP}}$ are all in agreement with this.

The $\alpha_{\mathrm{AP}}$ at high $\omega_{0}$ should be treated with caution. First, it cannot be excluded that the large variation of $\alpha_{\mathrm{AP}}$ at high $\omega_{0}$ is due to noise in raw aethalometer data at low concentrations, as discussed above in Sect. 2.4. Second, a possible source of large ranges of $\alpha_{\mathrm{AP}}$ at high $\omega_{0}$ is in the way absorption coefficients were calculated from the raw aethalometer data. The algorithm Eq. (2) that was used for this includes subtracting a fraction of $\sigma_{\mathrm{SP}}$ and summing of all absorption coefficients since the change of the filter spot. This cumulative nature of the algorithm inherently increases the uncertainty of the $\sigma_{\mathrm{AP}}$ data and thus also the derived quantities such as $\alpha_{\mathrm{AP}}$ and $\omega_{0}$ with time. Collaud-Coen et al. (2010) also noted that $\alpha_{\mathrm{AP}}$ derived from the Arnott et al. (2005) was noisy. A full error propagation of the formula has not been done.

\section{Classification according to air masses}

The range of aerosol intensive and extensive optical properties in different air masses was studied by comparing them with wind data measured at SMEAR II and by combining the data with backtrajectories. HYSPLIT4 (HYbrid Single-Particle Lagrangian Integrated Trajectory) trajectories (Draxler and Hess, 1998; Heinzerling, 2004; HYSPLITweb) were calculated for the arrival heights of $100 \mathrm{~m}$ and $500 \mathrm{~m}$ a.g.l. with hourly interval, $96 \mathrm{~h}$ back in time using NOAA FNL-archive data and NCEP/NCAR reanalysis data. 
(A)

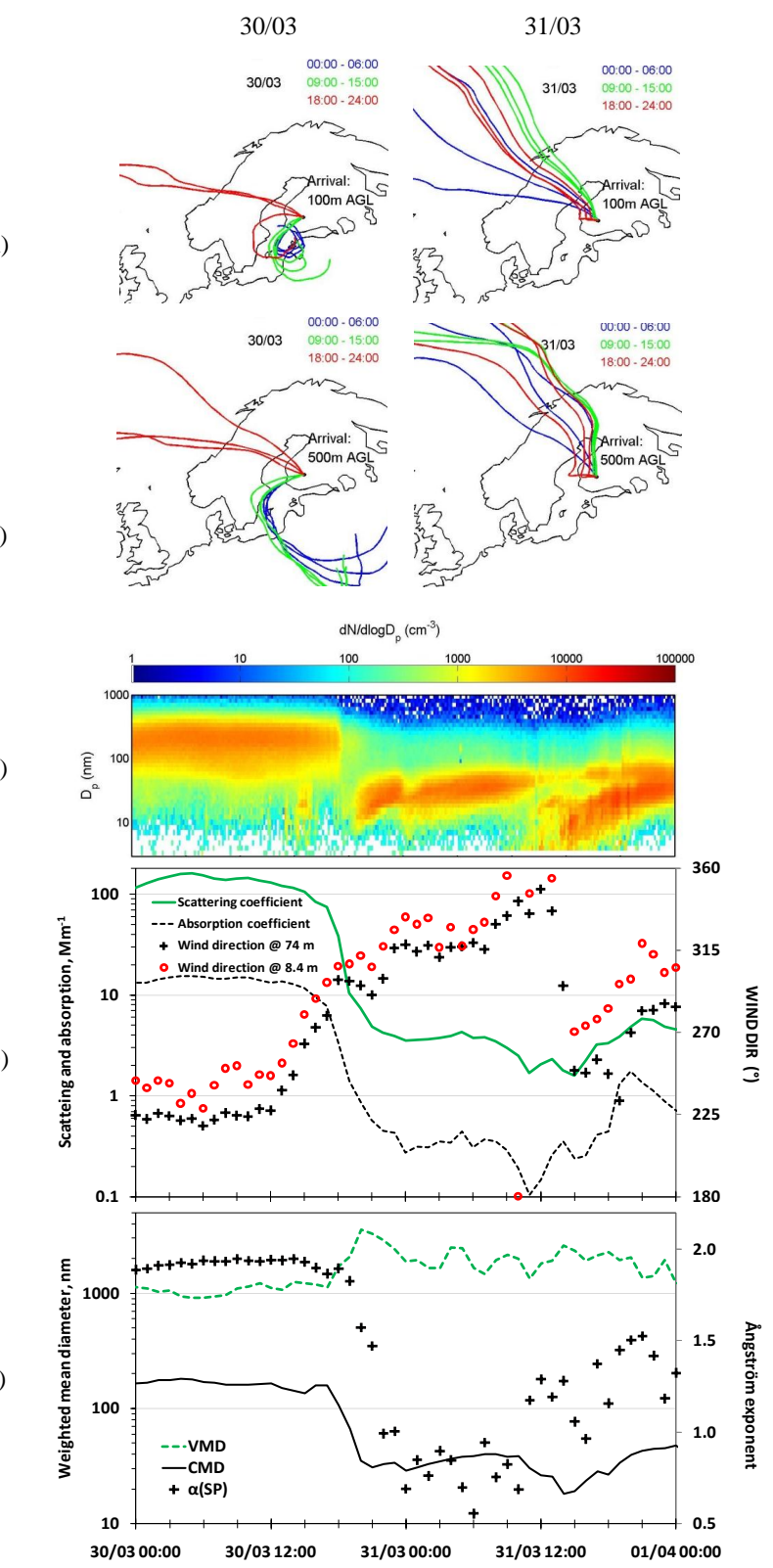

(B)

Fig. 15. Aerosol optical properties, size distributions, and air mass transport routes on 30-31 March 2007, the time is UTC $+2 \mathrm{~h}$. (A): HYSPLIT 4 backtrajectories arriving at SMEAR II $100 \mathrm{ma.g.1.;}$ (B): Backtrajectories arriving at $500 \mathrm{~m}$ a.g.l.; (C): Particle number size distributions; (D): $\sigma_{\mathrm{SP}}, \sigma_{\mathrm{AP}}$, and wind direction at two altitudes; (E) Volume mean diameter, count mean diameter, and Ångström exponent of scattering.

Below a two-day period is analyzed first, then the averages in wind direction sectors and finally a trajectory statistical analysis of selected parameters.

\subsection{Analysis of 30-31 March 2007}

The two-day period of 30-31 March 2007 was selected for a more detailed analysis since it shows the main features of variation of aerosol optical properties in different air masses (Fig. 15). On 30 March wind was from the SW, the wind direction was $230-250^{\circ}$ at $8.4 \mathrm{~m}$, i.e., within the forest canopy and more stable, $220-225^{\circ}$ at $74 \mathrm{~m}$ a.g.l. This may indicate that there was a counterclockwise spiral in the wind in the surface layer but further analysis has not been done on this. The main purpose for plotting the two wind direction time series was to show a typical situation at the site: wind turns close to the same direction at all the measured levels if there is strong enough wind to blow also within the canopy. During the whole analyzed period, for the data for which wind speed at the $8.4 \mathrm{~m}$ level was $>1 \mathrm{~m} \mathrm{~s}^{-1} 95 \%$ of the differences in wind directions were between $-20^{\circ}$ and $15^{\circ}$, the mean ( \pm standard deviation) difference was $-2 \pm 18^{\circ}$. Inspection of the uppermost plot in Fig. 15, shows that the backtrajectories that were calculated to arrive at $100 \mathrm{~m}$ a.g.l. have a common feature with the measurements: the last wind direction before arrival at Hyytiälä is close to that measured at the site. When the trajectories are followed further they show that continental air advected from Eastern Europe. It was a relatively highly polluted air mass with $\sigma_{\mathrm{SP}}>100 \mathrm{Mm}^{-1}$ and $\sigma_{\mathrm{AP}}>10 \mathrm{Mm}^{-1}$, with peak values of $146 \mathrm{Mm}^{-1}$ and $15 \mathrm{Mm}^{-1}$ at $\lambda=550 \mathrm{~nm}$. $\omega_{0}$ was stable at 0.89-0.91. In the particle number size distribution there was only one clear accumulation mode with $\mathrm{CMD} \approx 160$ $180 \mathrm{~nm}, N \approx 3600-4000 \mathrm{~cm}^{-3}$. VMD varied in the range 900-1100 $\mathrm{nm}$ and aerosol volume concentration in the range $26-29 \mu^{3} \mathrm{~cm}^{-3}$. Ångström exponent of scattering, $\alpha_{\mathrm{SP}}$ was stable at 1.91-1.94.

In the afternoon of 30 March wind direction veered so that it was first from the west and then later on 30 March and 31 March from the NW (270-340 $)$. The number size distribution changed markedly. The accumulation mode disappeared and the size distribution was dominated by nucleation and Aitken mode particles. CMD decreased markedly to $29-40 \mathrm{~nm}$ and $N$ to $1200-3000 \mathrm{~cm}^{-3}$ and $V$ decreased at the same time to $0.6-1.5 \mu \mathrm{m}^{3} \mathrm{~cm}^{-3}$. VMD, on the other hand increased to $1900-3500 \mathrm{~nm}$. At the same time when VMD increased $\sigma_{\mathrm{SP}}$ dropped to $3-4 \mathrm{Mm}^{-1}$ and $\sigma_{\mathrm{AP}}$ to 0.2 $0.3 \mathrm{Mm}^{-1}$, resulting in $\omega_{0}$ in the range $0.90-0.93$. The composition of these large particles is unclear. Sea salt particles are in this size range but the site is $>100 \mathrm{~km}$ from the nearest coast of the part of the Baltic Sea which at this time of the year is covered by ice, except shipping routes that are kept open by icebreakers. Some sea salt may be blown from these open channels but the amount is undoubtedly smaller than in summer. Another possibility is that the large particles are soil or pollen particles in spring. The wavelength dependency of scattering also changed clearly so that $\alpha_{\text {SP }}$ decreased to 0.6 0.9. Clean marine aerosol has been observed to have even lower $\alpha_{\text {SP }}$ (e.g., Quinn et al., 2000; Carrico et al., 2003) but 

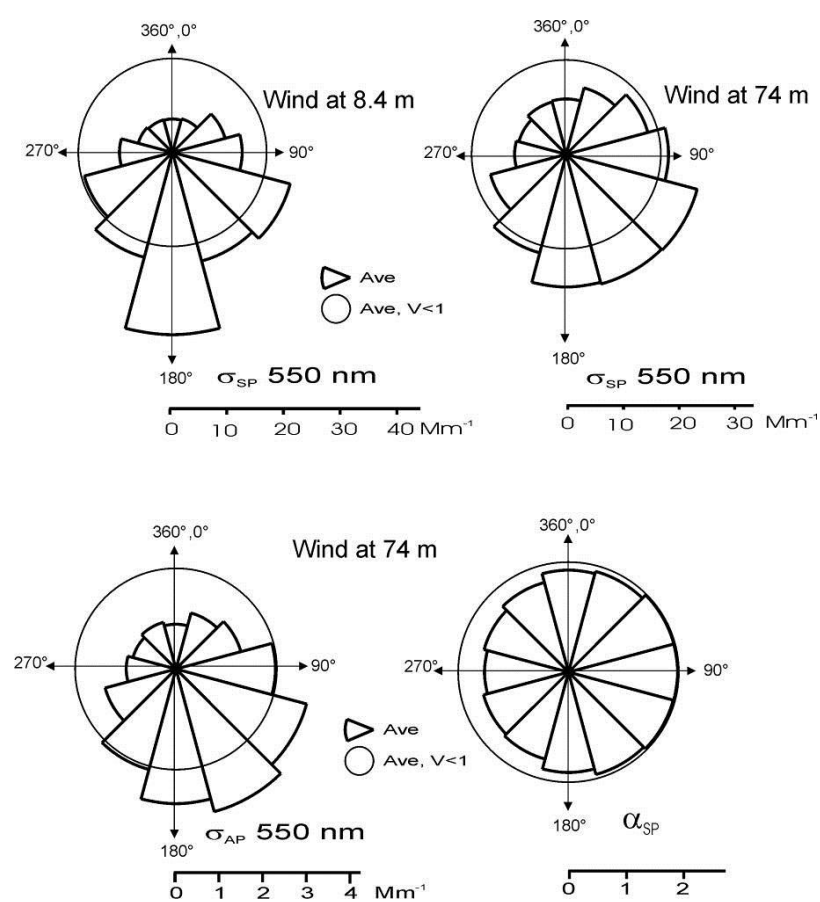

Fig. 16. Average scattering and absorption coefficients at $\lambda=$ $550 \mathrm{~nm}$ and Ångström exponent of scattering in 12 wind direction sectors during the whole analysis period. For $\sigma_{\mathrm{SP}}$ the classification was done both by using wind data measured at the lowest (8.4 m a.g.1.) and highest altitudes (74 m a.g.1.) in the SMEAR II meteorological mast.

the values are close to the average $\alpha_{\mathrm{SP}}$ of $0.77 \pm 0.32 \mathrm{ob}$ served for particles at the same size range $\left(D_{\mathrm{p}}<10 \mu \mathrm{m}\right)$ at an anthropogenically influenced marine station located in Nova Scotia (Delene and Ogren, 2002). So, even though the nearest part of the Baltic sea was covered with ice at the time, also the it may well be that some sea-salt particles did arrive at Hyytiälä.

On 31 March an obvious new particle formation event and subsequent growth was observed when the air masses came from the north, which has been shown to favor new particle formation at several Nordic stations (Tunved et al., 2003). Also the aerosol optical properties changed during the formation and growth event. Just before the appearance of the new particles at around noon the concentration of the Aitken mode particles at $D_{\mathrm{p}} \approx 80 \mathrm{~nm}$ decreased so that the mode almost disappeared and the total number concentration decreased from $3008 \mathrm{~cm}^{-3}$ to $1490 \mathrm{~cm}^{-3}$ and so did $\sigma_{\mathrm{SP}}$, from $3-4 \mathrm{Mm}^{-1}$ to $\sim 1.5 \mathrm{Mm}^{-1}$. When the freshly-formed particles first appeared at the observable sizes CMD decreased from about 40 to $<20 \mathrm{~nm}$ and subsequently the number size distributions showed growth of the freshly-formed particles and CMD. Simultaneously $\sigma_{\mathrm{SP}}$ increased from $\sim 1.5$ at 12:00 to $\sim 5.3 \mathrm{Mm}^{-1}$ at midnight. Also $\sigma_{\mathrm{AP}}$ varied during the particle formation and growth event. In the beginning, at noon it was $<0.1 \mathrm{Mm}^{-1}$ and $\omega_{0}>0.94$. Then also $\sigma_{\mathrm{AP}}$ increased and peaked to $1.1-1.6 \mathrm{Mm}^{-1}$ at 19:00-22:00 resulting in $\omega_{0}$ $0.73-0.84$, at midnight $\omega_{0}$ was again 0.9 . It cannot be ruled out that during the three hours absorption was influenced by local black carbon emissions. There is no clear indication of this in the size distributions, however, the growth of particles obviously continues as it normally does during the particle formation events.

It is clear that the growing nucleation mode particles have negligible contribution to scattering since they are so small, but something did happen also in the optically significant size range at the same time. The wavelength dependency of scattering changed again: $\alpha_{\mathrm{SP}}$ grew from $<1$ before the event to $1.0-1.2$ at the beginning of the event and close to 1.5 during the growth of the particles. A possible explanation is that the material that is responsible for the growth of the nucleation mode particles condensed on the larger particles as well and made them grow and also changed their optical properties. This would be consistent with Lihavainen et al. (2009) and Tunved et al. (2006). They observed that at the Pallas GAW station in Lapland $\sigma_{\mathrm{SP}}$ increased with increasing residence time over the continent and explained this by condensation of organics on particles. The case analyzed here is complicated because air mass transport route changed - even though not much for those trajectories that arrived at $100 \mathrm{~m}$ a.g.l. - at the same time as the growth was observed, so the data does not prove that the change in optical properties was due to growth. More cases like this have to be analyzed, the way it was done with the above-mentioned Pallas GAW data, to get statistically significant results.

\subsection{Classification into wind sectors}

It was shown above that aerosol optical properties clearly varied with wind direction during the selected two-day period. To get a more general picture of how wind data is related to the optical properties, the statistics of of $\sigma_{\mathrm{SP}}, \sigma_{\mathrm{AP}}$, and $\alpha_{\mathrm{SP}}$ were calculated after classifying the data into 12 wind sectors of $30^{\circ}$ width (Fig. 16). Wind measured at $8.4 \mathrm{~m}$ above ground and $74 \mathrm{~m}$ above ground were used. The 13th class was the measurements that were made at wind speeds $<1 \mathrm{~m} \mathrm{~s}^{-1}$. At wind speeds lower than that wind direction is very unreliable and they were classified as calm.

The lowest averages and medians of $\sigma_{\mathrm{SP}}, \sigma_{\mathrm{AP}}$, were observed in the NW and N sectors and highest in the SE sector, when the wind from the $74 \mathrm{~m}$ altitude was used. The wind rose drawn using the $8.4 \mathrm{~m}$ wind data shows that the highest average $\sigma_{\mathrm{SP}}$ is measured in the southern sector whereas if the $74 \mathrm{~m}$ wind data are used the highest sector is the SE, as it is also for $\sigma_{\mathrm{AP}}$. There is also a clear dependency of average $\alpha_{\mathrm{SP}}$ on wind sectors, as was expected from the episode analysis. For $\alpha_{\mathrm{SP}}$ the highest averages (1.91) were directly from the east, and lowest (1.47) from the west, so its wind sector distribution is somewhat different than that of $\sigma_{\mathrm{SP}}$ and $\sigma_{\mathrm{AP}}$. 
Table 4. Statistics of $\sigma_{\mathrm{SP}}$ and $\sigma_{\mathrm{AP}}$ at $\lambda=550 \mathrm{~nm}$ and Ångström exponent of scattering in the $74 \mathrm{~m}$ altitude wind sectors where average $\sigma_{\mathrm{SP}}$ were highest and lowest. Units as in Table 1.

\begin{tabular}{l|rr|rr}
\hline & \multicolumn{2}{|c|}{$120^{\circ}$} & \multicolumn{2}{|c}{$300^{\circ}$} \\
\cline { 2 - 5 } & AVE \pm STD & MED & AVE \pm STD & MED \\
\hline$\sigma_{\mathrm{SP}}(550 \mathrm{~nm})$ & $24 \pm 21$ & 18 & $8.8 \pm 9.4$ & 5.9 \\
$\sigma_{\mathrm{AP}}(550 \mathrm{~nm})$ & $3.1 \pm 2.7$ & 2.6 & $1.0 \pm 1.2$ & 0.71 \\
$\alpha_{\mathrm{SP}}$ & $1.9 \pm 0.3$ & 1.9 & $1.5 \pm 0.6$ & 1.6 \\
\hline
\end{tabular}

The averages, standard deviations and medians of $\sigma_{\mathrm{SP}}$, $\sigma_{\mathrm{AP}}$, and $\alpha_{\mathrm{SP}}$ in the wind sectors $120^{\circ}$ and $300^{\circ}$ where the average $\sigma_{\mathrm{SP}}$ was highest and lowest are also presented in Table 4 . The average scattering and absorption coefficients were roughly 3 times higher from the SE sector than from the NW sector.

The local contamination sources are to the west of the measurement cottage, as discussed in Sect. 2.1. The effect of these can be found in the analysis of selected episodes, as in the previous section. However, it is not obvious in the wind roses of absorption, the average $\sigma_{\mathrm{AP}}$ is almost the lowest in the western wind sector (Fig. 16). The percentiles of $\omega_{0}$ cumulative distributions in the different wind sectors and in the calm data $\left(<1 \mathrm{~m} \mathrm{~s}^{-1}\right)$ are shown in Fig. 17, as well as the contribution of data from these sectors. The median values in each sector are about 0.9 in all sectors and also in the calm data. The lowest median $(0.87)$ is in the sector $150^{\circ}$. But when the lowest 10 percentile of each sector and the calm data are considered, the calm data stands out clearly: the darkest aerosol is observed during when there is little wind, which suggests the low $\omega_{0}$ values are due to local aerosol. The low winds represent only a small fraction, $0.3 \%$ of the data. When the wind was greater than $1 \mathrm{~m} \mathrm{~s}^{-1}$ from the western sector $\left(270^{\circ}\right)$, even the lowest 2.5 th percentile is not lower than the surrounding sectors, the lowest sectors are $150-210^{\circ}$ like in the medians.

\subsection{Trajectory statistical analysis}

In addition to case studies the trajectory and measurement data were analyzed statistically. At each time step the measured value of the chosen optical parameter was assigned to the grid cells $\left(1^{\circ} \times 1^{\circ}\right)$ along the corresponding back trajectory so that the arrival time of the trajectory was equal to the measurement time. The geometric mean of values accumulated to each grid cell was calculated. The result is a concentration field that suggests for each cell passed by air masses on the way to Hyytiälä, whether it contributed to relatively high or low values monitored at the receptor site. In order to ensure the statistical significance of the result, the geometric mean was calculated only if a minimum number of trajectories, set to 10 in this work, crossed a grid cell. It should be

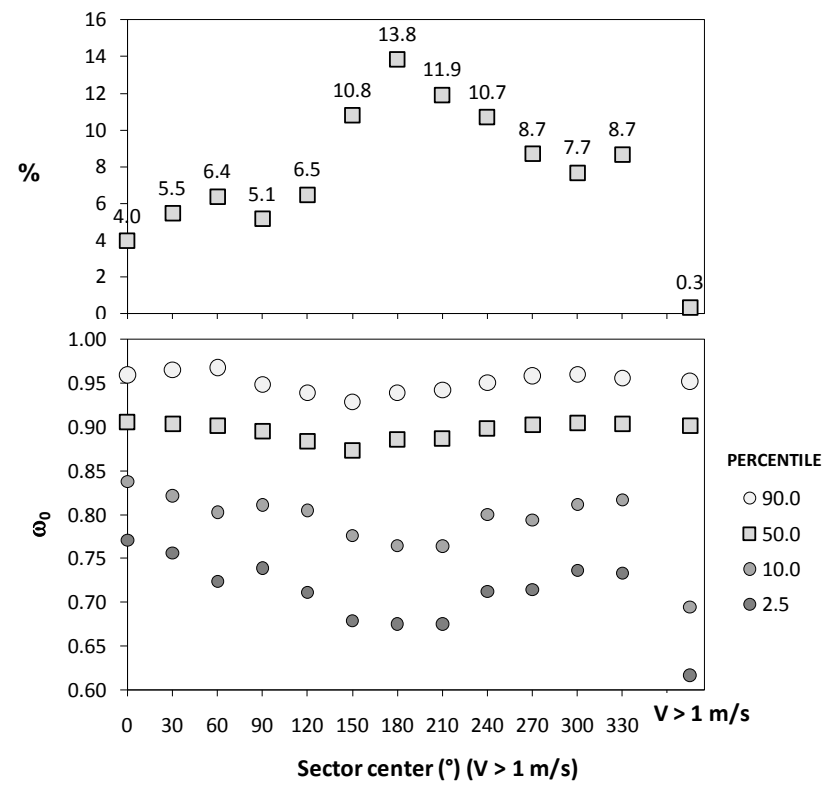

Fig. 17. Selected percentiles of cumulative distributions of $\omega_{0}$ in 12 wind sectors and in the calm data $\left(v<1 \mathrm{~m} \mathrm{~s}^{-1}\right)$ (lower panel), and the contribution of data from these sectors (upper panel).

explicitly mentioned here that this is not a source-receptor relationship, no emission inventories are used in this kind of an approach, only measurement data at the field station. This is a frequency of occurrence plot for the motion of air parcel trajectories across geographical regions.

The uncertainty related to calculated HYSPLIT4 trajectories is estimated to be 10 to $30 \%$ of the travelled distance ( 15 to $30 \%$ by Heinzerling (2004), 10 to $20 \%$ by Draxler and Hess (1998)). To see how much the uncertainty can effect the result, It it is was taken into account by assigning a weighted concentration value also to grid cells surrounding the trajectory path. Cells closer than $10 \%$ of the trajectory travelling distance were given a concentration value weighted by 0.70 and those farther than $10 \%$ but closer than $20 \%$ of the travelled distance got a concentration weighted by 0.30 . The choice of factors was made assuming a normally distributed probability of trajectory error. The resulting field was then normalized by the maximum value occurring in it. This results in a scale from 0 to 1 and the interpretation comes down to comparing each cell with the surrounding field. The method differs slightly from the so called nine point filter suggested by Stohl (1996), where the first guess concentration field is followed by an iterative redistribution procedure to improve spatial resolution.

The analysis was done for $\sigma_{\mathrm{SP}}$ and $\sigma_{\mathrm{AP}}$ at $\lambda=550 \mathrm{~nm}$ and $\alpha_{\mathrm{SP}}(450-700 \mathrm{~nm}$. The analysis shows that the highest values of $\sigma_{\mathrm{SP}}$ and $\sigma_{\mathrm{AP}}$ were associated with trajectories from Eastern Europe (Fig. 18). This is in agreement with the wind rose analysis above. Also the actual values according to the statistical trajectory method and the wind rose analysis are in 

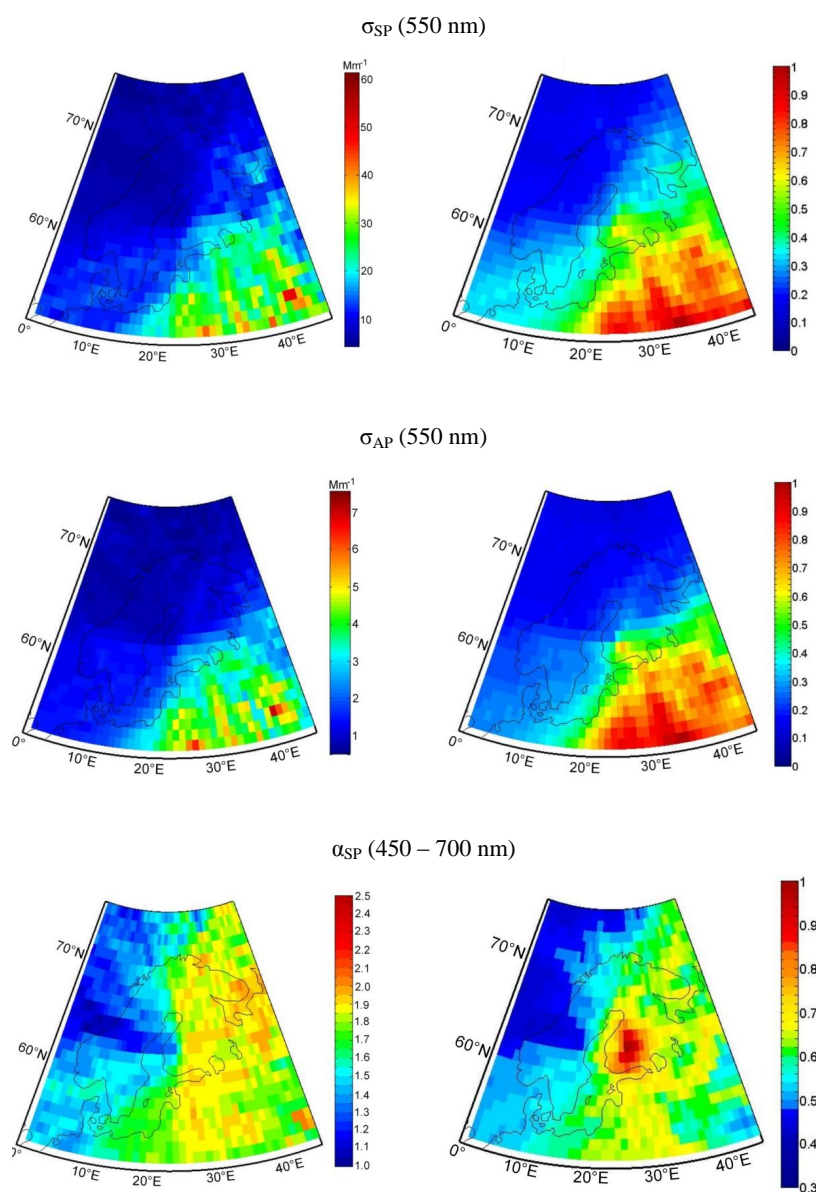

SP $(450-700 \mathrm{~nm})$

Fig. 18. Trajectory statistics of scattering and absorption coefficients at $\lambda=550 \mathrm{~nm}$ and the Ångström exponent of scattering. Left: absolute values, right: normalized values, see text for explanation.

good agreement: in the SE wind sector $\left(120^{\circ}\right)$ the average and median of $\sigma_{\mathrm{SP}}$ were 24 and $18 \mathrm{Mm}^{-1}$ (Table 4) and the trajectory statistics show that the geometric mean $\sigma_{\mathrm{SP}}$ associated with the grid cells in Eastern Europe was in the range of $20-40 \mathrm{Mm}^{-1}$. Similarly, the geometric means of $\sigma_{\mathrm{SP}}$ in the grid cells over Norwegian Sea were in the range of 5$10 \mathrm{Mm}^{-1}$ which agrees with the average and median $\sigma_{\mathrm{SP}}$ in the NW wind sector $\left(300^{\circ}\right), 8.8$ and $5.9 \mathrm{Mm}^{-1}$, respectively (Table 4). Similar agreement is found between $\sigma_{\mathrm{AP}}$ and $\alpha_{\mathrm{SP}}$ values in Fig. 18 and Table 4.

Additionally, agreement can be found in terms of the geographical location of the source area of relatively high $\alpha_{\mathrm{SP}}$ values: both the wind rose and the trajectory method suggest it to be norther than that for $\sigma_{\mathrm{SP}}$ and $\sigma_{\mathrm{AP}}$. This suggests that there are differences in the average particle size distributions associated with aerosols coming from the various source region. This will not be analyzed further in the present work, however.

It has to be emphasized here that the above comparison of the wind sectors and the trajectory statistical results does not imply that always when it blows from the south at Hyytiälä air masses have come from Central or Eastern Europe some days earlier or that when it blows from the north air masses have come from the Arctic Sea. It may well be just the opposite in some episodes and for instance in frontal passages. However, when statistics of long time series are calculated, local northern wind directions at Hyytiälä are associated with air masses coming from the Arctic Sea and southern winds with air masses coming from continental Europe.

When taking the trajectory uncertainty into account, it becomes clear that no quantitative conclusions can be drawn with accuracy from the trajectory approach. Qualitatively, however, the results match with those presented above and clearly identify sectors of air mass paths that result in high values of optical parameters observed in Hyytiälä.

\section{Summary and conclusions}

The basic aerosol optical properties, scattering and absorption, measured at the SMEAR II station in Hyytiälä, Finland, from October 2006 to May 2009 were analyzed. Basic statistical values of all data were presented, together with seasonal and diurnal cycles in four seasons, as well as relationships with each other and particle size distributions. Finally source regions were analyzed both by comparing the data with local wind data and by applying a trajectory statistical method.

The average scattering coefficient $\sigma_{\mathrm{SP}} 18 \mathrm{Mm}^{-1}$ at $\lambda=$ $550 \mathrm{~nm}$ was more than twice as much as at the Pallas GAW station in Finnish Lapland. Also the seasonal cycle was somewhat different than at the GAW station, and the ratio of the highest to smallest monthly average $\sigma_{\mathrm{SP}}$ was smaller than that at Pallas. A probable explanation to this type of seasonal cycle is that winter aerosol is dominated by continental pollution aerosol and in summer by biogenic aerosol, and in Hyytiälä the amount of biogenic organic aerosol is higher than in Lapland. The seasonal cycle of absorption was much clearer. The lowest monthly-averaged single-scattering albedos $\left(\omega_{0}\right)$ were observed in winter $(\sim 0.86)$ and highest in summer $(\sim 0.91)$. This is most probably due to emissions from heating with wood and coal both in Finland and the rest of Europe in the cold season.

The diurnal cycles of $\sigma_{\mathrm{SP}}$ and $\sigma_{\mathrm{AP}}$ were not very strong but in spring and summer they could be observed in medians and averages. The minimum of $\sigma_{\mathrm{AP}}$ was in the afternoon but $\sigma_{\mathrm{SP}}$ did not have such a clear minimum which lead to a maximum of $\omega_{0}$ at noon or afternoon. A possible explanation is that this is due to condensation of some low-volatile material, most probably biogenic secondary organics in a forest, on existing particles. If the existing particles contain light absorbing carbon (LAC), $\omega_{0}$ will increase due to the condensation.

$\sigma_{\mathrm{SP}}$ was highly correlated with the volume concentrations integrated from the size distributions measured with a DMPS and an APS yielding the $\mathrm{PM}_{10}$ mass scattering efficiency 
of $3.1 \pm 0.9 \mathrm{~g} \mathrm{~m}^{-2}$ at $\lambda=550 \mathrm{~nm}$, assuming that the particle density was $1.5 \mathrm{~g} \mathrm{~cm}^{-3}$. There was also a clear positive correlation between the measured $\sigma_{\mathrm{SP}}$ and the condensation sink (CS) calculated from the size distributions. Models suggest that high CS limits new particle formation so the good correlation between CS and $\sigma_{\mathrm{SP}}$ suggest that in case no size distribution data are available at some site but there is a nephelometer, the $\sigma_{\mathrm{SP}}$ could potentially be used for estimating CS and thus also the potential for new particle formation.

Scattering coefficients were also calculated from the number size distributions by using a Mie code and the refractive index of ammonium sulfate. The linear regression yielded $\sigma_{\mathrm{SP}}($ modelled $)=1.046 \times \sigma_{\mathrm{SP}}($ measured $)$ for the data with the low nephelometer relative humidity $\left(\mathrm{RH}_{\mathrm{NEPH}}=30 \pm 9 \%\right)$ and $\sigma_{\mathrm{SP}}($ modelled $)=0.985 \times$ $\sigma_{\mathrm{SP}}\left(\right.$ measured) when $\mathrm{RH}_{\mathrm{NEPH}}=55 \pm 4 \%$. There were also large deviations from the regression line: $10 \%$ of the $\sigma_{\mathrm{SP}}\left(\right.$ modelled)-to- $\sigma_{\mathrm{SP}}$ (measured) ratios, calculated for each hour, were smaller than 0.9 and $10 \%$, i.e., the 90th percentile are larger than 1.27. These deviations could almost all be eliminated by taking also absorption and thus the imaginary refractive index into account in the Mie modelling. The effective complex refractive index was obtained by an iterative approach, by matching the measured and the modelled $\sigma_{\mathrm{SP}}$ and $\sigma_{\mathrm{AP}}$. The average effective complex refractive index was $(1.517 \pm 0.057)+(0.019 \pm 0.015) i$ at $\lambda=550 \mathrm{~nm}$. The real part was close to that of ammonium sulfate. The iterated imaginary part had a strong seasonal cycle, with smallest values in summer and highest in winter.

The integrand of the formula for modeling scattering coefficient can be called the scattering size distribution. These were bimodal: they had a large submicron mode with geometric mean diameters $D_{\mathrm{g}}$ between $\sim 300$ and $400 \mathrm{~nm}$ and a smaller supermicron mode with $D_{\mathrm{g}}$ at $\sim 1.5-1.9 \mu \mathrm{m}$. The average contribution of submicron particles to scattering was $\sim 90 \%$, but it varied somewhat so that it was highest in winter and lowest in summer. The average contribution of sub$100 \mathrm{~nm}$ particles to scattering was less than about $0.2 \%$, even though their contribution to particle number concentration was approximately $80 \%$.

The Ångström exponent $\alpha$ describes the wavelength dependency of scattering, absorption and extinction. For scattering and extinction it is commonly used as a qualitative indicator of aerosol particle size, with large $\alpha(>2)$ indicating the dominance of small particles, and small $\alpha(<1)$ the dominance of large particles. Here the Ångström exponent of scattering, $\alpha_{\mathrm{SP}}$, was compared with the several weighted mean diameters: count mean diameter (CMD), surface mean diameter (SMD), scattering mean diameter (ScMD), condensation sink mean diameter (CsMD), and volume mean diameter (VMD). If $\alpha_{\mathrm{SP}}$ is to be used for estimating some measure of the size of particles, the best choice would be ScMD, then SMD, and then VMD. In all of these the qualitative relationship is similar: the larger the Ångström exponent, the smaller the weighted mean diameter. And further, for all of these the relationship is qualitatively the same as that for the modelled monomodal size distribution. For CMD the relationship was opposite and the correlation coefficient was low. This is due to the small contribution of particles smaller than $100 \mathrm{~nm}$ to scattering. So the Ångström exponent cannot really be used for describing the number size distribution. The CsMD did not vary significantly as a function of $\alpha_{\mathrm{SP}}$.

The lowest averages and medians of $\sigma_{\mathrm{SP}}, \sigma_{\mathrm{AP}}$, were observed in the NW and N sectors and highest in the SE sector, when the wind from the $74 \mathrm{~m}$ altitude was used. Local contamination sources to the west of the measurement cottage were seen in the single-scattering albedo in calm conditions, i.e., when wind speed was $<1 \mathrm{~m} \mathrm{~s}^{-1}$. The western sectoral average of the absorption coefficient was one of the lowest in the wind sector analysis.

The trajectory statistical analysis showed that the sources of the largest scattering and absorption coefficients were in Eastern Europe. The geometric mean $\sigma_{\mathrm{SP}}$ and $\sigma_{\mathrm{AP}}$ associated with the grid cells in Eastern Europe were in the range 20$40 \mathrm{Mm}^{-1}$ and $4-6 \mathrm{Mm}^{-1}$, respectively. The respective geometric means of $\sigma_{\mathrm{SP}}$ and $\sigma_{\mathrm{AP}}$ in the grid cells over Norwegian Sea were in the range $5-10 \mathrm{Mm}^{-1}$ and $<1 \mathrm{Mm}^{-1}$. Interestingly, the trajectory statistical $\sigma_{\mathrm{SP}}$ values are in close agreement with a similar analysis made of $\sigma_{\mathrm{SP}}$ measured at the Sevettijärvi measurement station in Eastern Finnish Lapland more than ten years earlier in 1994-1995: there the geometric mean $\sigma_{\mathrm{SP}}$ associated with grid cells in Central Europe and over Norwegian Sea were in the range of $20-30 \mathrm{Mm}^{-1}$ and $2-5 \mathrm{Mm}^{-1}$, respectively (Virkkula et al., 1997). The source areas associated with high $\alpha_{\mathrm{SP}}$ values were norther than those for $\sigma_{\mathrm{SP}}$ and $\sigma_{\mathrm{AP}}$. A good agreement was found between the trajectory statistics and the wind sector classification, when wind data from the altitude of $74 \mathrm{~m}$ was used.

Acknowledgements. This work was supported by the Academy of Finland as part or the Centre of Excellence program (project no 1118615), the European Commission 6th framework program project (EUCAARI), contract 036833-2, by the EU FP6 Integrated Infrastructures Initiatives (I3) project EUSAAR (European Supersites for Atmospheric Aerosol Research, project FP6-026140), the ESA-ESRIN project STSE-ALANIS Atmosphere Land Interaction Study, Theme 3 Aerosols, and the Maj and Tor Nessling foundation, Finland (project nr. 2009399).

Edited by: A. Wiedensohler

\section{References}

Aalto, P. P. and Kulmala, M.: Using a cloud condensation nuclei counter to study CCN properties and concentrations, Boreal Environ. Res., 5, 349-359, 2000.

Aalto, P., Hämeri, K., Becker, E., Weber, R., Salm, J., Mäkelä, J. M., Hoell, C., O’Dowd, C. D., Karlsson, H., Hansson, H.-C., Väkevä, M., Koponen, I. K., Buzorius, G., and Kulmala, M.: Physical characterization of aerosol particles during nucleation events, Tellus B, 53, 344-358, 2001. 
Aaltonen, V., Lihavainen, H., Kerminen, V.-M., Komppula, M., Hatakka, J., Eneroth, K., Kulmala, M., and Viisanen, Y.: Measurements of optical properties of atmospheric aerosols in Northern Finland, Atmos. Chem. Phys., 6, 1155-1164, doi:10.5194/acp-6-1155-2006, 2006.

Anderson, T. L. and Ogren, J. A.: Determining aerosol radiative properties using the TSI 3563 Integrating Nephelometer, Aerosol Sci. Technol., 29, 57-69, 1998.

Anderson, T. L., Covert, D. S., Marshall, S. F., Laucks, M. L., Charlson, R. J., Waggoner, A. P., Ogren, J. A., Caldow, R., Holm, R. L., Quant, F. R., Sem, G. J., Wiedensohler, A., Ahlquist, N. A., and Bates, T. S.: Performance characteristics of a high-sensitivity, three-wavelength total scatter/backscatter nephelometer, J. Atmos. Ocean. Tech., 13, 967-986, 1996.

Andrews, E., Sheridan, P. J., Fiebig, M., McComiskey, A., Ogren, J. A., Arnott, P., Covert, D., Elleman, R., Gasparini, R., Collins, D., Jonsson, H., Schmid, B., and Wang, J.: Comparison of methods for deriving aerosol asymmetry parameter, J. Geophys. Res., 111, D05S04, doi:10.1029/2004JD005734, 2006.

Arnott, W. P., Hamasha, K., Moosmüller, H., Sheridan, P. J., and Ogren, J. A.: Towards aerosol light-absorption measurements with a 7-wavelength aethalometer: evaluation with a photoacoustic instrument and 3-wavelength nephelometer, Aerosol Sci. Technol. 39, 17-29, 2005.

Ångström, A.: On the atmospheric transmission of sun radiation and on dust in the air, Geogr. Ann., 11, 156-166, doi:10.2307/519399, 1929.

Barber, P. W. and Hill, S. C.: Light scattering by particles: Computational methods, World Scientific Publishing, Singapore, 1990.

Bergstrom, R. W., Pilewskie, P., Russell, P. B., Redemann, J., Bond, T. C., Quinn, P. K., and Sierau, B.: Spectral absorption properties of atmospheric aerosols, Atmos. Chem. Phys., 7, 5937-5943, doi:10.5194/acp-7-5937-2007, 2007.

Bond, T. C. and Bergstrom, R. W.: Light absorption by carbonaceous particles: An investigative review, Aerosol Sci. Technol., 40, 27-67, 2006.

Carrico, C. M., Kus, P., Rood, M. J., Quinn, P. K., and Bates, T. S.: Mixtures of pollution, dust, sea salt, and volcanic aerosol during ACE-Asia: Radiative properties as a function of relative humidity, J. Geophys. Res., 108(D23), 8650, doi:10.1029/2003JD003405, 2003.

Casati, R., Scheer, V., Vogt, R., and Benter, T.: Measurement of nucleation and soot mode particle emission from a diesel passenger car in real world and laboratory in situ dilution, Atmos. Environ., 10, 2125-2135, 2007.

Charlson, R. J., Ahlquist, N. C., and Horvath, H.: On the generality of correlation of atmospheric aerosol mass concentration and light scatter, Atmos. Environ., 2, 455-464, 1967.

Chow, J. C., Watson, J. G., Doraiswamy, P., Chen, L.-W., Sodeman, D. A., Lowenthal, D. H., Park, K., Arnott, W. P., and Motallebi, N.: Aerosol light absorption, black carbon, and elemental carbon at the Fresno Supersite, California, Atmos. Res., 93, 874-887, 2009.

Collaud-Coen, M., Weingartner, E., Apituley, A., Ceburnis, D., Fierz-Schmidhauser, R., Flentje, H., Henzing, J. S., Jennings, S. G., Moerman, M., Petzold, A., Schmid, O., and Baltensperger, U.: Minimizing light absorption measurement artifacts of the Aethalometer: evaluation of five correction algorithms, Atmos. Meas. Tech., 3, 457-474, doi:10.5194/amt-3-457-2010, 2010.
Dal Maso, M., Kulmala, M., Lehtinen, K., Mäkelä, J., Aalto, P., and O'Dowd, C.: Condensation and coagulation sinks and formation of nucleation mode particles in coastal and boreal forest boundary layers, J. Geophys. Res., 107(D19), 8097, doi:10.1029/2001JD001053, 2002.

Dal Maso, M., Kulmala, M., Riipinen, I., Wagner, R., Hussein, T., Aalto, P. P., and Lehtinen, K. E. J.: Formation and growth of fresh atmospheric aerosols: eight years of aerosol size distribution data from SMEAR II, Hyytiälä, Finland, Boreal Environ. Res., 10, 323-336, 2005.

DeCarlo, P., Slowik, J. G., Worsnop, D. R., Davidovits, P., and Jimenez, J. L.: Particle Morphology and Density Characterization by Combined Mobility and Aerodynamic Diameter Measurements. Part 1: Theory, Aerosol Sci. Technol., 38, 11851205, 2004.

Delene, D. J. and Ogren, J. A.: Variability of Aerosol Optical Properties at Four North American Surface Monitoring Sites, J. Atmos. Sci., 59, 1135-1150, 2002.

Draxler, R. and Hess, G. An Overview of the HYSPLIT 4 modelling system for trajectories, dispersion and deposition, Aust. Meteorol. Mag., 47, 295-308, 1998.

Ehn, M., Petäjä, T., Aufmhoff, H., Aalto, P., Hämeri, K., Arnold, F., Laaksonen, A., and Kulmala, M.: Hygroscopic properties of ultrafine aerosol particles in the boreal forest: diurnal variation, solubility and the influence of sulfuric acid, Atmos. Chem. Phys., 7, 211-222, doi:10.5194/acp-7-211-2007, 2007.

Engler, C., Lihavainen, H., Komppula, M., Kerminen, V.-M., Kulmala, M., and Viisanen, Y.: Continuous measurements of aerosol properties at the Baltic Sea, Tellus B, 59, 728-741, 2007.

Garland, R. M., Yang, H., Schmid, O., Rose, D., Nowak, A., Achtert, P., Wiedensohler, A., Takegawa, N., Kita, K., Miyazaki, Y., Kondo, Y., Hu, M., Shao, M., Zeng, L. M., Zhang, Y. H., Andreae, M. O., and Pöschl, U.: Aerosol optical properties in a rural environment near the mega-city Guangzhou, China: implications for regional air pollution, radiative forcing and remote sensing, Atmos. Chem. Phys., 8, 5161-5186, doi:10.5194/acp-85161-2008, 2008.

Garland, R. M., Schmid, O., Nowak, A., Achtert, P., Wiedensohler, A., Gunthe, S. S., Takegawa, N., Kita, K., Kondo, Y., Hu, M., Shao, M., Zeng, L. M., Zhu, T., Andreae, M. O., and Pöschl, U.: Aerosol optical properties observed during Campaign of Air Quality Research in Beijing 2006 (CAREBeijing2006): Characteristic differences between the inflow and outflow of Beijing city air, J. Geophys. Res., 114, D00G04, doi:10.1029/2008JD010780, 2009.

Gobbi, G. P., Kaufman, Y. J., Koren, I., and Eck, T. F.: Classification of aerosol properties derived from AERONET direct sun data, Atmos. Chem. Phys., 7, 453-458, doi:10.5194/acp-7-453-2007, 2007.

Hari, P. and Kulmala, M.: Station for Measuring EcosystemAtmosphere Relations (SMEAR II), Bor. Env. Res., 10, 315-322, 2005.

Haywood, J. M. and Shine, K. P.: The effect of anthropogenic sulfate and soot aerosol on the clear sky planetary radiation budget, Geophys. Res. Lett., 22(4), 603-606, 1995.

Heinzerling, D.: Automation of HYSPLIT trajectory generation and subsequent analysis, Washington university, Research for Undergraduates Program 2004, 2004.

Higurashi, A. and Nakajima, T.: Development of a Two-Channel 
Aerosol Retrieval Algorithm on a Global Scale Using NOAA AVHRR, J. Atmos. Sci., 56, 924-941, 1999.

Hobbs, P. V., Reid, J. S., Kotchenruther, R. A., Ferek, R. J., and Weiss, R.: Direct Radiative Forcing by Smoke from Biomass Burning, Science, 275, 1777-1778, 1997.

Holben, B. N., Tanré, D., Smirnov, A., Eck, T. F., Slutsker, I., Abuhassan, N., Newcomb, W. W., Schafer, J. S., Chatenet, B., Lavenu, F., Kaufman, Y. J., Castle, J. V., Setzer, A., Markham, B., Frouin, D. C. R., Halthore, R., Karneli, A., O’Neill, N. T., Pietras, C., Pinker, R. T., Voss, K., and Zibordi, G.: An emerging ground-based aerosol climatology: Aerosol optical depth from AERONET, J. Geophys. Res., 106, 12067-12098, 2001.

Hulkkonen, M., Pitoisuuskenttämenetelmän käytettävyys lähdealueanalyysissä: Testausta ja arviointia $\mathrm{SO}_{2}$ pitoisuusmittausten ja HYSPLIT_4-trajektorien avulla. M. Sc. Thesis (in Finnish), University of Helsinki, Department of Physics, 2010.

Hulkkonen, M., Dal Maso, M., Riuttanen, L., Junninen, H., and Kulmala, M.: Trajectory-based source area analysis of atmospheric $\mathrm{CO}_{2}, \mathrm{O}_{3}, \mathrm{NO}_{\mathrm{x}}, \mathrm{SO}_{2}$ and particulate matter from the perspective of a Finnish measurement station in 1996-2008, Rep. Ser. Aer. Sci., 109, available at: www.atm.helsinki.fi/FAAR/ reportseries/, 2010.

Hyvärinen, A.-P., Kolmonen, P., Kerminen, V.-M., Virkkula, A., Leskinen, A., Komppula, M., Hatakka, J., Burkhart, J., Stohl, A., Aalto, P., Kulmala, M., Lehtinen, K. E. J., Viisanen, Y., and Lihavainen H.: Aerosol black carbon at five background measurement sites over Finland, a gateway to the Arctic, Atmospheric Environment, in press, 2011.

HYSPLIT-web: ARL Air Resources Laboratory: HYSPLIT - Hybrid Single Particle Lagrangian Integrated Trajectory Model, available at: http://ready.arl.noaa.gov/HYSPLIT.php, 2011.

Kannosto, J., Virtanen, A., Lemmetty, M., Mäkelä, J. M., Keskinen, J., Junninen, H., Hussein, T., Aalto, P., and Kulmala, M.: Mode resolved density of atmospheric aerosol particles, Atmos. Chem. Phys., 8, 5327-5337, doi:10.5194/acp-8-5327-2008, 2008.

King, M. D., Kaufman, Y. J., Tanré, D., and Nakajima, T.: Remote sensing of tropospheric aerosols from space: Past, present, and future, B. Am. Meteorol. Soc., 80, 2229-2259, 1999.

Kirchstetter, T. W., Novakov, T., and Hobbs, P. V.: Evidence that the spectral dependence of light absorption by aerosols is affected by organic carbon, J. Geophys. Res., 109, D21208, doi:10.1029/2004JD004999, 2004.

Kittelson, D. B.: Engines and nanoparticles: A Review, J. Aerosol Sci., 29, 575-588, 1998.

Kulmala, M., Toivonen, A., Mäkelä, J. M., and Laaksonen, A.: Analysis of the growth of nucleation mode particles observed in Boreal forest, Tellus B, 50, 449-462, 1998.

Kulmala, M., Rannik, Ü., Pirjola, L., Dal Maso, M., Karimäki, J., Asmi, A., Jäppinen, A., Karhu, V., Korhonen, H., Malvikko, S.P., Puustinen, A., Raittila, J., Romakkaniemi, S., Suni, T., YliKoivisto, S., Paatero, J., Hari, P., and Vesala, T.: Characterization of atmoshperic trace gas and aerosol concentrations at forest sites in southern and northern Finland using back trajectories, Boreal Environ. Res., 5, 315-336, 2000.

Kulmala, M., Petäjä, T., Mönkkönen, P., Koponen, I. K., Dal Maso, M., Aalto, P. P., Lehtinen, K. E. J., and Kerminen, V.-M.: On the growth of nucleation mode particles: source rates of condensable vapor in polluted and clean environments, Atmos. Chem. Phys.,
5, 409-416, doi:10.5194/acp-5-409-2005, 2005.

Kyrö, E.-M., Grönholm, T., Vuollekoski, H., Virkkula, A., Kulmala, M., and Laakso, M.: Snow scavenging of ultrafine particles: field measurements and parameterization, Boreal Environ. Res., 14, 527-538, 2009.

Lewis, K., Arnott, W. P., Moosmüller, H., and Wold, C. E.: Strong spectral variation of biomass smoke light absorption and single scattering albedo observed with a novel dual-wavelength photoacoustic instrument, J. Geophys. Res., 113, D16203, doi:10.1029/2007JD009699, 2008.

Lihavainen, H., Kerminen, V.-M., Tunved, P., Aaltonen, V., Arola, A., Hatakka, J., Hyvärinen, A., and Viisanen, Y.: Observational signature of the direct radiative effect by natural boreal forest aerosols and its relation to the corresponding first indirect effect, J. Geophys. Res., 114, D20206, doi:10.1029/2009JD012078, 2009.

Liu, H., Pinker, R. T., Chin, M., Holben, B., and Remer, L.: Synthesis of information on aerosol optical properties, J. Geophys. Res., 113, D07206, doi:10.1029/2007JD008735, 2008.

Malm, W.C. and Hand, J.L.: An examination of the physical and optical properties of aerosols collected in the IMPROVE program, Atm. Env. 41, 3407 - 3427, 2007.

Manninen, H. E., Nieminen, T., Riipinen, I., Yli-Juuti, T., Gagné, S., Asmi, E., Aalto, P. P., Petäjä, T., Kerminen, V.-M., and Kulmala, M.: Charged and total particle formation and growth rates during EUCAARI 2007 campaign in Hyytiälä, Atmos. Chem. Phys., 9, 4077-4089, doi:10.5194/acp-9-4077-2009, 2009.

Mészáros, E., Molnár, A., and Ogren, J.: Scattering and absorption coefficients vs. chemical composition of fine atmospheric aerosol particles under regional conditions in Hungary, J. Aerosol Sci., $29,1171-1178,1998$.

Mikhailov, E., Vlasenko, S., Podgorny, I., Ramanathan, V., and Corrigan, C.: Optical properties of soot-water drop agglomerates: An experimental study, J. Geophys. Res., 111, 1-16, 2006.

Mäkelä, J. M., Aalto, P., Jokinen, V., Pohja, T., Nissinen, A., Palmroth, S., Markkanen, T., Seitsonen, K., Lihavainen, H., and Kulmala, M.: Observations of ultrafine aerosol particle formation and growth in boreal forest, Geophys. Res. Lett., 24, 1219-1222, 1997.

Ogren, J. A.: A systematic approach to in situ observations of aerosol properties, in: Aerosol Forcing of Climate, edited by: Charlson, R. J. and Heintzenberg, J., John Wiley, 215-226, 1995.

Pirjola, L., Kulmala, M., Wilck, M., Bischoff, A., Stratmann, F., and Otto, E.: Effects of aerosol dynamics on the formation of sulphuric acid aerosols and cloud condensation nuclei, J. Aerosol Sci., 30, 1079-1094, 1999.

Quinn, P. K., Bates, T. S., Coffman, D. J., Miller, T. L., Johnson, J. E., Covert, D. S., Putaud, J.-P., Neusüß, C., and Novakov, T.: A comparison of aerosol chemical and optical properties from the $1 \mathrm{st}$ and $2^{\text {nd }}$ Aerosol Characterization Experiments, Tellus B, 52, 239-257, 2000.

Saarikoski, S., Mäkelä, T., Hillamo, R., Aalto, P., Kerminen, V.-M., and, Kulmala, M.: Physico-chemical characterization and mass closure of size-segregated atmospheric aerosols in Hyytiälä, Finland, Boreal Environ. Res., 10, 385-400, 2005.

Scheifinger, H. and Kaiser, A.: Validation of trajectory statistical methods, Atmos. Environ., 41, 8846-8856, 2007.

Schnaiter, M., Horvath, H., Mohler, O., Naumann, K. H., Saathoff, H., and Schock, O. W.: UV-VIS-NIR spectral optical properties 
of soot and soot-containing aerosols, J. Aerosol Sci., 34, 14211444, 2003.

Schnaiter, M., Gimmler, M., Llamas, I., Linke, C., Jäger, C., and Mutschke, H.: Strong spectral dependence of light absorption by organic carbon particles formed by propane combustion, Atmos. Chem. Phys., 6, 2981-2990, doi:10.5194/acp-6-2981-2006, 2006.

Schuster, G. L., Dubovik, O., and Holben, B. N.: Angstrom exponent and bimodal aerosol size distributions, J. Geophys. Res., 111, D07207, doi:10.1029/2005JD006328, 2006.

Sheridan, P. J. and Ogren, J. A.: Observations of the vertical and regional variability of aerosol optical properties over central and eastern North America, J. Geophys. Res., 104, 16793-16805, 1999.

Sogacheva, L., Dal Maso, M., Kerminen, V.-M., Kulmala, M. Probability of nucleation events and aerosol particle concentration in different air mass types arriving at Hyytiälä, southern Finland, based on back trajectory analysis, Boreal Environ. Res., 10, 479491, 2005.

Stohl, A.: Trajectory statistics - a new method to establish sourcereceptor relationships of air pollutants and its application to the transport of particulate sulfate in Europe, Atmos. Environ., 30, 579-587, 1996.

Stohl, A.: Computation, accuracy and applications of trajectories A review and bibliography, Atmos. Environ., 32, 947-966, 1998.

Tunved, P., Hansson, H.-C., Kulmala, M., Aalto, P., Viisanen, Y., Karlsson, H., Kristensson, A., Swietlicki, E., Dal Maso, M., Strm, J., and Komppula, M.: One year boundary layer aerosol size distribution data from five nordic background stations, Atmos. Chem. Phys., 3, 2183-2205, doi:10.5194/acp-3-2183-2003, 2003.
Tunved, P., Hansson, H. C., Kerminen, V. M., Ström, J., Dal Maso, M. H., Lihavainen, Y., Viisanen, P. P., Aalto, M., Komppula, M., and Kulmala, M.: High natural aerosol loading over boreal forests, Science 312, 261-263, 2006.

Van de Hulst, H. C.: Light Scattering by Small Particles, Wiley, New York, 1957.

Virkkula, A., Hillamo, R. E., Kerminen, V.-M., and Stohl, A.: The influence of Kola Peninsula, continental European and marine sources on the number concentrations and scattering coefficients of the atmospheric aerosol in Finnish Lapland, Boreal Env. Res., 2(4), 317-336, 1997.

Virkkula A., Koponen I. K., Teinilä K., Hillamo R., Kerminen V.-M., and Kulmala M.: Effective real refractive index of dry aerosols in the Antarctic boundary layer, Geophys. Res. Lett., 33, L06805, doi:10.1029/2005GL024602, 2006.

Virkkula, A., Mäkelä, T., Yli-Tuomi, T., Hirsikko, A., Koponen, I. K., Hämeri, K., and Hillamo, R.: A simple procedure for correcting loading effects of aethalometer data, J. Air Waste Manage., 57, 1214-1222, 2007.

Weingartner, E., Saathoff, H., Schnaiter, M., Streit, N., Bitnar, B., and Baltensperger, U.: Absorption of light by soot particles: determination of the absorption coefficient by means of aethalometers, J. Aerosol Sci., 34, 1445-1463, 2003.

WMO: WMO/GAW Aerosol Measurement Procedures Guidelines and Recommendations, (WMO TD No. 1178) - GAW Report No. 153, World Meteorological Organization, Geneva, 2003. 